ALESSANDRA SOARES

MINERAIS ORGÂNICOS NA ALIMENTAÇÃO DE POTROS

Pirassununga

2007 


\section{ALESSANDRA SOARES}

\section{MINERAIS ORGÂNICOS NA ALIMENTAÇÃO DE POTROS.}

Dissertação apresentada ao Programa de PósGraduação em Nutrição e Produção Animal da Faculdade de Medicina Veterinária e Zootecnia da Universidade de São Paulo para obtenção do título de Mestre em Medicina Veterinária

\section{Departamento:}

Nutrição e Produção Animal

Área de concentração:

Nutrição e Produção Animal

Orientador:

Prof. Dr. Alexandre Augusto de Oliveira Gobesso 
Autorizo a reprodução parcial ou total desta obra, para fins acadêmicos, desde que citada a fonte.

DADOS INTERNACIONAIS DE CATALOGAÇÃO-NA-PUBLICAÇÃO

(Biblioteca Virginie Buff D’Ápice da Faculdade de Medicina Veterinária e Zootecnia da Universidade de São Paulo)

FMVZ

Soares, Alessandra

Minerais orgânicos na alimentação de potros / Alessandra Soares. -- Pirassununga: A. Soares 2007.

72 f. : il.

Dissertação (mestrado) - Universidade de São Paulo. Faculdade de Medicina Veterinária e Zootecnia. Departamento de Nutrição e Produção Animal, 2007.

Programa de Pós-Graduação: Nutrição e Produção Animal. Área de concentração: Nutrição e Produção Animal.

Orientador: Prof. Dr. Alexandre Augusto de Oliveira Gobesso.

1. Biopsia óssea. 2. Cavalos. 3. Densitometria óssea. 4. Minerais. 5. Quelatos. I. Título. 


\section{UNIVERSIDADE DE SÃO PAULO \\ Faculdade de Medicina Veterinária e Zootecnia \\ Comissão Bioética}

CERTIFICADO

Certificamos que o Projeto intitulado "Minerais orgânicos na alimentação de potros", protocolado sob o no849/2006, utilizando 10 (dez) cavalos, sob a responsabilidade do Prof. Dr. Alexandre Augusto de Oliveira Gobesso, está de acordo com os princípios éticos de experimentação animal da Comissão de Bioética da Faculdade de Medicina Veterinária e Zootecnia da Universidade de São Paulo e foi aprovado em reunião de 14/06/06".

(We certify that the Research "Organic minerals in diet of foals", protocol number $849 / 2006$, utilizing 10 (ten) horses, under the responsibility of Prof. Dr. Alexandre Augusto de Oliveira Gobesso, agree with Ethical Principles in Animal Research adopted by Bioethic Commission of the School of Veterinary Medicine and Animal Science of University of São Paulo and was approved in the meeting of the day 06/14/2006).

São Paulo, 23 de outubro de 2007

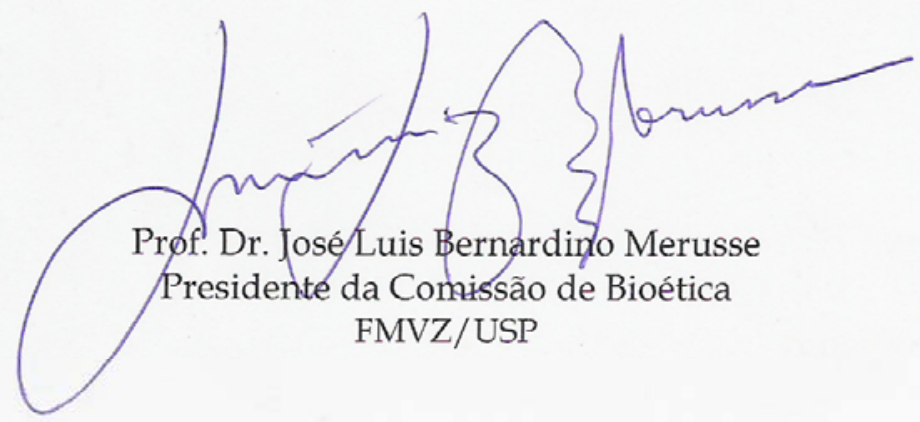


Nome: SOARES, Alessandra

Título: Minerais orgânicos na alimentação de potros

Dissertação apresentada ao Programa de Pós-Graduação em Nutrição e Produção Animal da Faculdade de Medicina Veterinária e Zootecnia da Universidade de São Paulo para obtenção do título de Mestre em Medicina Veterinária

Data:

\section{Banca Examinadora}

Prof. Dr. Instituição:

Assinatura: Julgamento:

Prof. Dr. Instituição:

Assinatura: Julgamento:

Prof. Dr. Instituição:

Assinatura: Julgamento: 
"Não se contente em trilhar um caminho estabelecido ao contrário, vá pra onde não há caminho e deixe seu rastro."

(Muriel Strode) 


\section{Ofereço}

A DEUS, sempre presente em minha vida, orientando meus passos e iluminando todas as minhas decisões, me abençoando e fortalecendo em todos os momentos.

\section{Dedico}

A meus pais, Benedito e Cleusa pertencem este momento de minha vida; vocês que tanto colaboraram e lutaram para hoje estar aqui e que sonharam antes de mim com este dia, jamais poderei ser suficientemente grata. Pela realização deste ideal, minha homenagem, admiração e gratidão. Dedico a vocês essa vitória. 


\section{Agradecimentos}

Ao meu orientador, Prof. Dr. Alexandre Augusto de Oliveira Gobesso, apoio neste trabalho, e pelos ensinamentos durante estes anos de convívio.

Ao programa de Pós-graduação em Nutrição e Produção Animal da Faculdade de Medicina Veterinária e Zootecnia da Universidade de São Paulo USP/ Pirassununga, pela oportunidade de realização deste curso.

A Tortuga Cia. Zootécnica Agrária, pelo fornecimento do material para condução do experimento, pelo fornecimento das rações, pelo conhecimento no assunto, e pela oportunidade de realizar e concluir esse curso.

Em especial ao Dr. Ricardo Leandro Cazes, pelos preciosos ensinamentos e orientação, e pela dedicação, confiança, paciência e amizade nestes anos, aos questionamentos que levaram a formação de novas idéias, meus agradecimentos sinceros.

Ao meu amigo Alexandre Sechinato, pela amizade, ensinamentos, e palavras de incentivo em todos esses anos.

Aos grandes amigos Rodrigo e Waleska, pela dedicação, amizade, apoio, inestimável ajuda e participação ativa na condução dos experimentos.

Ao Dr. Thiago Salles Gomes, pela disponibilidade, incentivo e sugestões para a realização desse experimento.

Ao Dr. Mauricio Bittar, pela disponibilidade, ajuda na realização das radiografias.

A todos os amigos do curso de Pós-Graduação, pela amizade, apoio, companheirismo e convivência, pelos momentos alegres que passamos juntos, e pela ajuda nessa caminhada.

Não poderia deixar de agradecer a grande ajuda dos funcionários da cocheira que muito ajudaram durante o período de experimento.

Ao meu primo Marcos, sua esposa Elaine, e sua filha Julia, pelo carinho, apoio e auxílio durante todos os momentos.

Aos meus amigos da Tortuga, a minha grande amiga Denise, pelo carinho e dedicação durante todos esses anos.

A todos que de algum modo, me incentivaram e me acompanharam nessa jornada, meu sincero agradecimento. Frequentemente, meu cansaço e 
preocupação foram sentidos por vocês e compartilhados por vocês. Tantas foram às vezes que me distancie de vocês, apegando-me nos livros. A alegria dessa conquista também é sua. Afinal, seu amor, estímulo, carinho e compreensão são a alma desta vitória, Obrigada! 


\section{RESUMO}

SOARES, A. Minerais orgânicos na alimentação de potros. [Organic mineral in diet of foals]. 2007. 72 f. Dissertação (Mestrado em Medicina Veterinária) Faculdade de Medicina Veterinária e Zootecnia, Universidade de São Paulo, Pirassununga, 2007.

O objetivo do trabalho foi avaliar o uso de minerais orgânicos na alimentação de potros, avaliando a deposição óssea de Cálcio e Fósforo, através de biopsia e densitometria óssea, além das medidas de crescimento, de altura da cernelha e da garupa, perímetro torácico, joelho, canela e ganho de peso. Foram utilizados dez potros com idade entre 10 e 13 meses e peso aproximado de $221 \mathrm{~kg}$, distribuídos aleatoriamente em dois tratamentos: dieta formulada com minerais orgânicos e dieta formulada com minerais inorgânicos, com cinco repetições por tratamento. A dieta foi composta de $40 \%$ de volumoso, feno de gramínea e $60 \%$ de concentrado, a qual foi adicionada $3 \%$ da mistura mineral orgânico ou inorgânico. Não foi observada diferença entre os tratamentos em relação ao consumo da deita, medidas de crescimento, e deposição óssea de cálcio e fósforo. No entanto, a deposição óssea dos animais do tratamento orgânico foram maiores quando comparada com as médias do tratamento inorgânico. Entretanto para a variável densitometria, a deposição óssea dos potros alimentados com fonte orgânica foi maior aos 90 dias, quando comparado com todos os animais do tratamento com fonte inorgânica. Os animais do tratamento orgânico apresentaram melhor ganho de peso médio e diário em relação aos animais que receberam mineral inorgânico.

Palavras-chave: Biopsia óssea. Cavalos. Densitometria óssea. Minerais. Quelatos. 


\begin{abstract}
SOARES, A. Organic mineral in diet of foals. [Minerais orgânicos na alimentação de potros]. 2007. 72 f. Dissertação (Mestrado em Medicina Veterinária) - Faculdade de Medicina Veterinária e Zootecnia, Universidade de São Paulo, Pirassununga, 2007.

The aim of this study was to evaluate the effects of mineral organic in the diet of foals, evaluating the bone mineral deposit of calcium and phosphorus, throughout biopsy and bone mineral density, measures of growing was also did measuring height withers and croup, thoracic circumference, knee, cannon and weight gain. Ten foals which approximated 10 and 13 months and almost $221 \mathrm{Kg}$ weight each one were spread randomly into two treatments: diet with organic mineral and diet with inorganic mineral both with five repetitions for treatments. The diet were composed by $40 \%$ of roughage and $60 \%$ for concentrate, with was addition $3 \%$ of mixed mineral organic or inorganic. It was not detected any for consumption of diet, either for measures of growing and bone mineral concentration of calcium and phosphorus. Nevertheless, the average bone mineral concentration for organic treatment was better than mineral inorganic supplementation. However, the concentration in bone mineral was greater for organic treatment which was better for bone mineral density and weight. The bone deposition was better in 90 days of treatment. Therefore, the diet with organic mineral for foals probably better for bone mineral density and weight gain.
\end{abstract}

Key Words: Bone biopsy. Bone densitometry. Chelated. Horses. Mineral. 


\section{LISTA DE FIGURAS}

Figura 1 - (A) sistema haversiano, aparecem como anéis; periósteo, endósteo, (B) osteoblasto, osteócito e osteoclatos.

Figura 2 - Osteoblasto. Presença de grande quantidade de organelas indica a característica de célula sintetizadora de substâncias.

Figura 3 - $\quad$ Osteócito. Ramificações estreitas permitem a comunicação com outras células através da matriz.

Figura 4 - Osteoclasto. As vilosidades otimizam o processo de absorção de elementos exteriores ao proporcionar uma maior área de contato do osteoclasto com o tecido ósseo.

Figura 5 - Desenho esquemático da vista lateral e frontal do terceiro metacarpo de um eqüino, e sua localização no membro anterior.

Figura 6 - Desenho esquemático de um osso longo, sendo visíveis as epífises (osso trabecular) e a diáfise (osso cortical), além de outras estruturas

Figura 7 - Medidas de altura da cernelha (1) e da garupa (2), distância codilho-solo (3) e perímetro torácico (4)

Figura 8 - Medidas de comprimento da cabeça (5), do pescoço (6), da espádua (7), do dorso-lombo (8), da garupa (9) e do corpo (10), e perímetros do antebraço (11), joelho (12) e canela (13).

Figura 9 - $\quad$ Incisão da pele com divulsão do tecido subcutâneo por onde foi introduzida furadeira de baixa rotação para retirada do fragmento ósseo.

Figura 10 - Fragmento ósseo, comparando seu tamanho com a lâmina do bisturi

Figura 11 - Amostra de fragmentos ósseos acondicionados em álcool $70 \%$ com a identificação de cada animal e data da coleta para posterior análise.

Figura 12 - Radiografia do membro anterior direito na posição latero-lateral e dorso-palmar, com aparelho portátil

Figura 13 - Seleção da área da cunha e determinação da quantidade de pixels. 
Figura 14 - Seleção da área da cicatriz epifisária e determinação da quantidade de pixels................................................................ 


\section{LISTA DE TABELAS}

Tabela 1 - Quantidades em porcentagem de ingredientes utilizados na formulação do concentrado - Pirassununga - SP 2006.

Tabela 2 - Composição bromatologica dos componentes utilizados na dieta - Pirassununga - SP - 2006

Tabela 3 - Ingredientes utilizados na formulação das misturas minerais orgânicas e inorgânicas com os mesmo níveis de garantia São Paulo - SP - 2006.

Tabela 4 - Composição das misturas minerais orgânicas e inorgânicas São Paulo - SP - 2006.

Tabela 5 - Formação das duplas, distribuição nos tratamento de acordo com a idade dos animais e consequentemente datas de inicio e termino do experimento - Pirassununga - SP 2006.

Tabela 6 - Resultados obtidos para as médias de consumo de feno, concentrado e sal mineral orgânico e inorgânico $(\mathrm{kg})$ durante o período experimental, e os respectivos coeficientes de variação $(C V \%)$ e probabilidade estatística $(P)$ para os modelos estudados - Pirassununga - SP 2006.

Tabela 7 - Resultados referente à biopsia óssea para o tratamento e controle, bem como a Deposição (Dep.) de cálcio e fósforo nos ossos - Pirassununga - SP 2006

Tabela 8 - Valores médios de Cálcio e Fósforo para cada tempo entre o tratamento e o controle - Pirassununga - SP 2006.

Tabela 9 - Valores médios da deposição mineral óssea de cálcio e fósforo durante o período experimental, coeficiente de variação $(\mathrm{CV} \%)$ e probabilidade estatística $(\mathrm{P})$ para os tratamentos com mistura mineral orgânica e inorgânica Pirassununga $-\mathrm{SP}-2006$

Tabela 10 - Resultados obtidos para os valores médios em centímetros das avaliações de desenvolvimento dos potros, sendo elas: perímetro de canela $(\mathrm{PC})$, de joelho $(\mathrm{PJ})$, torácico $(\mathrm{PT})$, altura 
de garupa ( $A G)$, de cernelha ( $A C)$, além dos resultados para ganho de peso médio $(\mathrm{GPM} / \mathrm{kg})$ e ganho de peso diário (GPD/kg), bem como os respectivos coeficientes de variação (CV\%) e probabilidade estatística (P.) - Pirassununga - SP 2006 


\begin{tabular}{ll} 
AC & Altura de cernelha \\
AG & Altura de garupa \\
ANOVA & Analise de variância \\
ATP & Adenosina tri-fosfato \\
C & Controle \\
CV & Coeficiente de variação \\
DMO & Densidade mineral óssea \\
DOD & Doenças ortopédicas do desenvolvimento \\
ED & Energia digestível \\
EE & Extrato etéreo \\
FB & Fibra bruta \\
FDN & Fibra detergente neutro \\
GPD & Ganho de peso diário \\
GDM & Ganho de peso médio \\
kV & Quilo voltagem \\
mAS & Miliamperagem por segundo \\
MS & Matéria seca \\
OCD & Osteocondrose \\
P & Probabilidade estatística \\
PC & Perímetro de canela \\
PB & Proteína bruta \\
PJ & Perímetro de joelho \\
PSI & Puro sangue inglês \\
PT & Perímetro torácico \\
T & Tratamento \\
\hline
\end{tabular}




\section{LISTA DE SÍMBOLOS}

$\begin{array}{ll}\% & \text { Porcentagem } \\ < & \text { Menor } \\ \mathrm{Ca} & \text { Maior } \\ \mathrm{cm} & \text { Cálcio } \\ \mathrm{P} & \text { Centímetros } \\ \mathrm{Kg} & \text { Fósforo } \\ \mathrm{mmAl} & \text { Quilograma } \\ \mathrm{g} / \mathrm{cm}{ }^{2} & \text { Milímetros de alumínio } \\ \mathrm{pH} & \text { Grama por centímetro quadrado } \\ \mathrm{h} & \text { Gradiente de acidez } \\ \mathrm{mcal} / \mathrm{kg} & \text { Horas } \\ \mathrm{n}^{\circ} & \text { Megacaloria por quilograma } \\ { }^{\circ} \mathrm{C} & \text { Número }\end{array}$




\section{SUMÁRIO}

1 INTRODUÇÃO

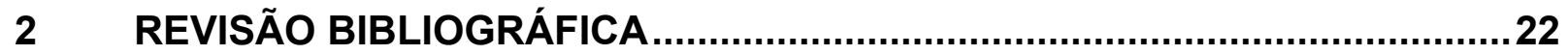

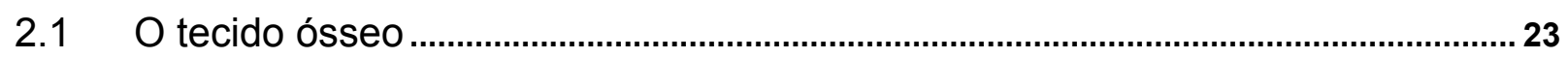

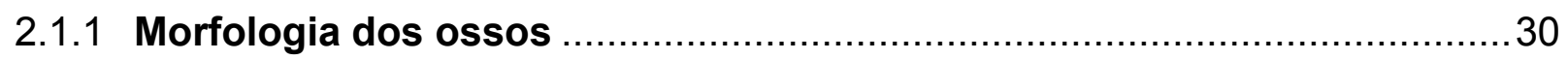

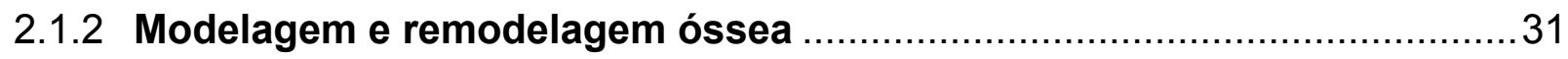

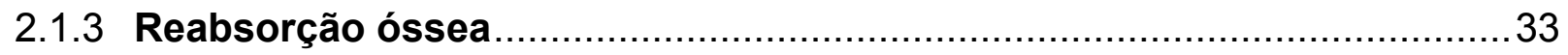

2.2 Cálcio e Fósforo ……………………………………………………………….....

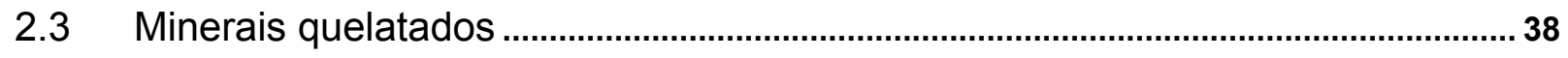

2.4 Biodisponibilidade e absorção dos quelatos ........................................................... 39

2.5 Avaliação do desenvolvimento de equinos .............................................................. 41

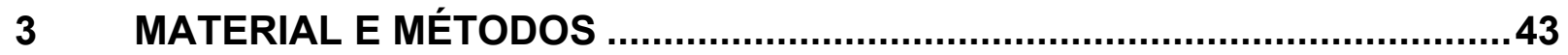

3.1 Local e animais .................................................................................................... 43

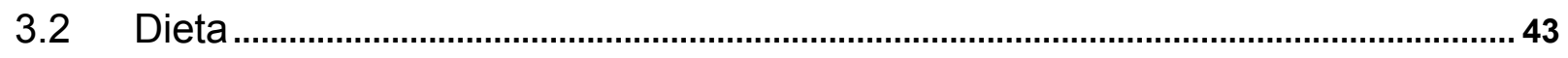

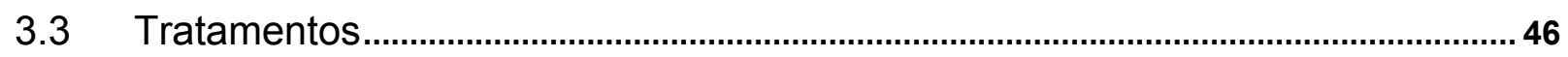

3.4 Avaliação do desenvolvimento ........................................................................... 47

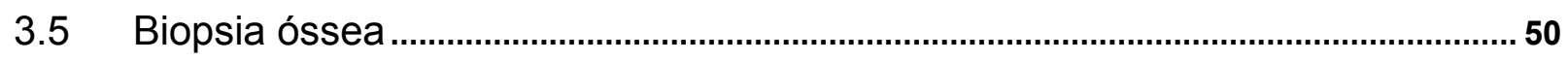

3.6 Densitometria óssea ........................................................................................

3.7 Delineamento experimental .............................................................................5

3.8 Análise estatística .................................................................................................56

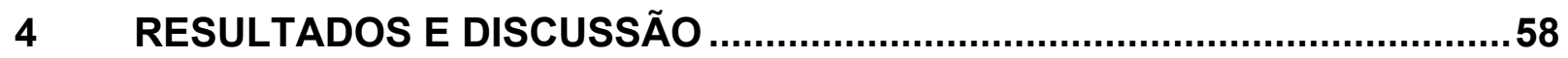

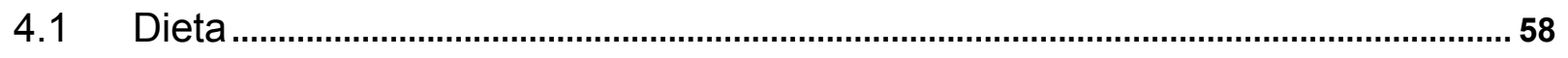

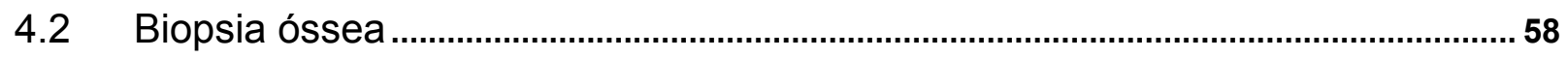

4.3 Avaliação do desenvolvimento ..............................................................................61

4.4 Densitometria óssea ............................................................................................

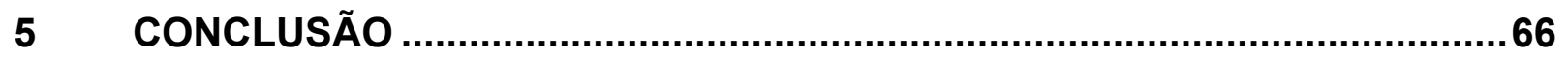

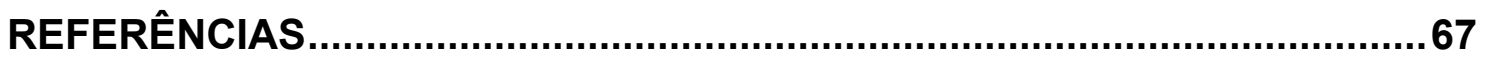




\section{INTRODUÇÃO}

O cavalo ocupa uma posição de destaque nos países desenvolvidos e em muitos daqueles em desenvolvimento. No entanto, a configuração do Agronegócio Cavalo no Brasil é ainda pouco conhecida, principalmente no que se refere à sua contribuição na geração de renda e de postos de trabalho. Mais grave: muitas vezes, a imagem do setor é distorcida e carregada de preconceitos. Para muitos, a indústria do cavalo está relacionada ao interesse restrito de uma elite e distante da realidade do brasileiro em geral (LIMA et al., 2006).

De acordo com Bondi (1988), as tendências têm mudado no que se refere à criação destes animais, já que as características físicas e o temperamento do cavalo de sela são diferentes das do cavalo de trabalho.

O treinamento de animais que ainda estão em fase de desenvolvimento, acarreta em falhas no processo de crescimento ósseo, ficando o animal predisposto a um curto tempo de vida útil para o esporte. Além disso, uma nutrição inadequada e alimentação desequilibrada favorecem o aparecimento de doenças ortopédicas do desenvolvimento (DOD).

Para se obter uma nutrição adequada, é necessário que o animal receba quantidades balanceadas de nutrientes, os quais podem ser divididos em: Proteína, Carboidratos, Lipídeos, Vitaminas e Minerais. Os minerais são considerados de grande importância na alimentação, pois participam de todos os processos bioquímicos corporais (LEWIS, 2000).

Conforme Jackson e Pagan (1993), a aplicação inadequada de complementos alimentares que não respeitam as diferentes necessidades nutricionais que variam para cada raça, estado fisiológico e o tipo de atividade física do animal, pode desencadear o surgimento de problemas osteoarticulares e tendinosos. Tanto as carências e desequilíbrios nutricionais, como o excesso de nutrientes ou nutrição desbalanceada geram as principais doenças ortopédicas. Também relatam Jackson 
e Pagan (1993) que a causa mais provável da ocorrência das osteocondroses (ODC) é uma deficiência ou desbalanço mineral.

Segundo Mcllwraith (1996), os ossos longos se desenvolvem a partir de uma cartilagem por um processo chamado de ossificação endocontral. No feto, o osso prematuro é composto inteiramente por cartilagem, sendo que à medida que o crescimento ocorre, as células mais velhas da cartilagem hipertrofiam e a matriz intersticial da zona de calcificação provisória torna-se mineralizada. Durante esse processo podem ocorrer anormalidades envolvidas no processo de desenvolvimento, que são geralmente classificados como DOD. Dentre elas estão fisites, OCD, síndrome de wobbler e deformidades angulares e flexurais (PAGAN, 2000).

Essas anormalidades podem envolver defeitos na ossificação endocondral, anormalidade na conformação óssea ou alterações metabólicas dentro do osso após sua formação. Podem também ser causada por processos degenerativos induzidos ou por traumatismos. Geralmente essas anormalidades são identificadas quando o cavalo vai para treinamento ou é submetido a esforço (MCLLWRAITH, 1996).

A OCD, um distúrbio na diferenciação celular na cartilagem em crescimento, pode levar a síndromes de osteocondrites dissecantes ou cistos ósseos subcontrais periarticulares, podendo afetar tanto a cartilagem articular como o disco metafisário (STASHAK, 1994).

De acordo com Mcllwraith (1996), a OCD ocorre predominantemente em animais jovens de crescimento rápido que têm alta ingestão de alimentos, principalmente a ingestão excessiva de energia. Portanto, os níveis adequados de Cálcio e Fósforo são essenciais para a mineralização e crescimento normais dos ossos.

Trabalhos realizados com aves, que apresentam grande interresse de estudo, pois são animais de produção, relatam que a baixa absorção de microminerais, que pode causar uma piora na qualidade da casca do ovo, está relacionada com a formação de complexos com outras substâncias no trato digestivo o que reduz a solubilidade desses elementos. Esse fato justifica o interesse crescente em explorar fatores que aumentam a absorção ou metabolização dos elementos traços. Fontes 
orgânicas ou quelatos dos minerais têm sido utilizadas devido a sua perspectiva de serem mais biodisponíveis (MABE, 2001).

Clydesdale (1998) afirma que um ligante forma um composto solúvel com o mineral sendo com isso melhor absorvido pela mucosa intestinal. Segundo Spears (1996) o ligante pode formar um complexo estável no trato gastrointestinal, evitando com isso que o mineral forme complexos insolúveis e dificulte a sua absorção.

Conforme Malleto (1997), durante a ação de fatores estressantes, seja de forma aguda ou crônica, vários minerais são mobilizados e posteriormente excretados em maior quantidade. Estes minerais suplementados na forma orgânica mostraram ter um poder de amenização do estresse.

Leeson e Summers (1997) afirmam que uma absorção 50\% maior dos minerais orgânicos poderia ser compensada com um aumento no nível dos minerais inorgânicos na dieta, mas que isso não é possível, pois ocorre efeito negativo de um mineral em alta dose na absorção de outro mineral. Um exemplo disso ocorre com o sulfato de manganês, cuja biodisponibilidade é baixa. Quando se aumenta o nível na dieta, soluciona-se o problema, mas causa um efeito adverso na utilização do Fósforo, Cálcio e Ferro.

Conforme relataram Lawrence et al. (1994) que a quantidade de minerais contidos nos ossos pode influenciar na resistência do esqueleto a injúrias. Em um estudo post-mortem do metacarpo de eqüinos a quantidade de minerais contidos no osso foi altamente correlacionada com força, elasticidade e carga para quebrar o osso, e essas características influenciam a resistência mecânica a injúrias.

Em estudo realizado em potros por McCarthy e Jeffcott (1992), que mediram os efeitos da atividade física e inatividade sobre os ossos, foi observado que houve remodelação mínima na córtex dorsal em animais em exercício e intensa modelação na formação óssea subperiostal. Em contraste, segundo os autores, nos animais em inatividade a remodelação óssea foi mais intensa e significativa e a formação óssea subperiostal menor.

De acordo com Lawrence et al. (1994), para a nutrição animal, as aferições biomecânicas dos ossos estão sendo muito utilizadas para determinar a biodisponibilidade dos minerais e a estabilidade dos nutrientes exigidos. 
O conteúdo das cinzas ósseas provavelmente é o meio mais efetivo para estimar a quantidade de minerais nos ossos, entretanto, esse processo se tornou impraticável em muitas situações de pesquisa com eqüinos. E com o avanço da tecnologia, muitas ferramentas e métodos começaram a ser utilizados para avaliar a densidade óssea (KAREN et al., 2000).

Segundo Peter, Moure e Remigio (2004), a deposição mineral nos ossos, apresenta boa correlação com as propriedades biomecânicas dos ossos, e pode ser usada como meio de avaliação. Segundo esses autores, um método muito usado de avaliação não invasiva in vivo para mensurar a influência da idade, dos fatores envolvidos com as fontes alimentares da dieta, treinamento, confinamento e outros para a quantificação da matéria mineral óssea em equivalência de milímetros de alumínio (mmAl) é a densitometria óptica radiográfica.

No que diz respeito ao uso de minerais quelatados a literatura ainda é muito controversa e não se pode afirmar que a suplementação com essas formas orgânicas trazem benefícios ao crescimento. Portanto, estudos devem ser realizados com o intuito de avaliar a resposta nos cavalos aos minerais quelatados em relação aos minerais inorgânicos, bem como estudos que avaliem a estabilidade da molécula do quelato no trato digestivo dos animais e a sua biodisponibilidade (SECHINATO, 2003).

Este projeto teve como objeto avaliar o efeito de dietas formuladas com minerais orgânicos e inorgânicos na alimentação de potros, mensurando parâmetros de posição de Cálcio e Fósforo nos ossos, densitometria óssea e avaliação de desenvolvimento. 


\section{REVISÃO BIBLIOGRÁFICA}

A produção do cavalo tornou-se muito importante no setor do agronegócio, surgindo a necessidade de pesquisas relacionadas a fatores fisiológicos, os quais afetam tanto a produção quanto o desempenho animal, influenciando, assim, a economia (NRC, 1989).

Além dos fatores genéticos, a disponibilidade de nutrientes também é muito importante para o desenvolvimento e crescimento do esqueleto em cavalos. Desta forma, devemos oferecer uma suplementação mineral equilibrada, visto que o excesso ou carência de um elemento mineral pode levar a patologias.

Nas áreas tropicais do Brasil, o desenvolvimento das pastagens de características tropicais, as alterações sazonais e a tendência à grande concentração de animais freqüentemente resultam em alimentação deficiente em minerais e no aparecimento de distrofias ósseas, que depreciam o valor econômico dos eqüinos e muitas vezes os inutilizam para o trabalho. Assim, os consumos deficientes, tóxicos, marginais e ideais variam para cada mineral e situação.

Os minerais estão envolvidos em um grande número de funções no organismo, incluindo formação estrutural dos componentes, co-fatores enzimáticos e transporte de energia. Muitos minerais são partes integrais de vitaminas, hormônios e aminoácidos (NRC, 1989).

Entretanto os elementos minerais constituem somente pequena fração do peso corporal (LEWIS, 2000).

Os macrominerais são necessários para a estrutura corporal e para a manutenção dos equilíbrios ácido-básico e hídrico corporal e do potencial transmembrânico para as funções celulares, condução nervosa e contração muscular. A maioria dos microminerais é exigida como componentes de metaloenzimas (LEWIS, 2000).

Dieta e exercício são fatores que afetam a densidade óssea e a força. $O$ descondicionamento ao exercício e a disponibilidade insuficiente de minerais na dieta 
diminuem a quantidade de Cálcio e a densidade óssea, podendo levar a injúrias ósseas. Alguns trabalhos têm demonstrado que eqüinos que entram em treinamento cedo apresentam mudanças na remodelação óssea, que podem levar a prejuízos futuros se houver deficiências minerais dietéticas (PORR et al., 1998).

\subsection{O tecido ósseo}

O tecido ósseo é um dos mais resistentes e rígidos do corpo animal. É o constituinte principal do sistema esquelético e têm várias funções, entre elas: dar suporte mecânico às partes moles, proteção a órgãos vitais e apoio aos músculos esqueléticos, convertendo as contrações em movimentos úteis. Os ossos funcionam ainda como depósito de minerais como o cálcio, fosfatos e outros íons, armazenando-os e liberando-os de maneira a controlar a sua concentração nos líquidos corporais (MOURE, 2001).

O esqueleto é o tecido conjuntivo primário de suporte dos vertebrados e é constituído de ossos de formas e tamanhos diferentes. O osso é dinâmico por toda a vida, modificando sua estrutura em resposta aos estresses internos e externos. Apresenta elevado conteúdo mineral, o que confere dureza e rigidez, além de apresentarem células únicas, os osteoblastos, osteoclastos e osteócitos. As atividades coordenadas das células ósseas resultam na formação do osso durante o período de crescimento, na manutenção do osso no animal adulto e na modificação óssea (WASSERMAN; KALLFELZ; GEORGE, 1996).

A principal função do tecido ósseo é a sustentação do esqueleto, sendo sujeito a fraturas quando sua resistência sofre colapso frente a uma força maior. As fraturas são passíveis de acontecer em qualquer espécie animal, em especial frente a grandes traumas. Entretanto, existem situações patológicas em que esta fragilidade está aumentada (SARAIVA; CASTRO, 2002). 
O osso ainda é considerado um órgão hematopoiético, pois ele é fonte de eritrócitos, hemoglobina, granulócitos e plaquetas (GETTY, 1986).

O crescimento ósseo é muito rápido em potros e qualquer alteração durante o desenvolvimento pode deixar um grande impacto na resistência óssea durante a vida adulta (BELL et al., 2001).

Segundo Hiney, Nielsen e Rosenstein (2004), estudando o efeito do exercício e confinamento no possível aumento da massa óssea em eqüinos, onde os grupos eram divididos em: animais em piquetes, animais confinados e sem atividade física e o último grupo animais confinados e com atividade física, o resultado obtido pelos autores através da mensuração radiográfica acoplada com cunha de alumínio, para medir a composição óssea não diferiu entre os tratamentos.

Para Hoekstra et al. (2007) transferência de animais jovens da pastagem para cocheiras tem demonstrado que isto pode resultar em uma diminuição da concentração de osteocalcina (ou proteína Gla, sua síntese é aumentada quando ocorre maior calcificação do tecido - indicativo da atividade osteoblástica), indicando uma baixa da atividade na formação óssea e diminuição da atividade física. Ainda de acordo com os autores, estudo em outras espécies animais também demonstrou uma diminuição da força óssea em resposta ao confinamento dos animais. E de acordo com o estudo realizado pelos mesmos autores a análise radiográfica demonstrou que o confinamento animal diminui a deposição óssea.

Buchholz-bryant (2001) obteve melhor resultado na retenção de Cálcio e Fósforo quando suplementou eqüinos com quantidades $275 \%$ acima da recomendação do NRC (1989) comparado com o controle $100 \%$ da recomendação do NRC (1989).

Segundo Wasserman, Kallfelz e George (1996), o osso pode ser dividido em três regiões: o corpo, chamado de diáfise, as extremidades do osso, as epífises, e a região intermediária, a metáfise. Durante a fase de crescimento do animal existe ainda uma região intermediária altamente cartilaginosa, a placa epifisária.

Quatro tipos diferentes de células estão associados especificamente com 0 osso: os osteoblastos, cuja função primária é a síntese e a secreção de componentes da matriz orgânica óssea e a participação na mineralização da matriz 
orgânica, sendo produtores de colágeno, o principal componente da matriz orgânica. Os osteócitos são derivados dos osteoblastos e são circundados pela matriz óssea, apresentam potencial para formar o tecido ósseo como para reabsorver a superfície óssea. Os osteoclastos são células de reabsorção óssea e estão localizados dentro do citoplasma. E por último, as células de revestimento ósseo que recobrem a superfície óssea que estão em processo de formação ou reabsorção, constituem uma "pseudomembrana", separando a superfície óssea dos fluidos extracelulares nas regiões em que não estão cobertas por outros tipos de células ósseas. Podem ainda ser precursores dos osteoblastos e ter uma função de regulação no processo de formação óssea (WASSERMAN; KALLFELZ; GEORGE,1996).

A figura 1 representa um desenho esquemático o osso e suas estruturas, onde (A) representa o sistema haversiano, que são lamelas de osso, arranjadas concentricamente em torno dos canais vasculares, aparecem como anéis; periósteo, a membrana que reveste a superfície externa do osso; endósteo, membrana fibrosa delgada que limita a cavidade medular e os canais haversianos. (B) osteoblasto, grande quantidade de organelas indica a característica de célula sintetizadora de substâncias; osteócito, as várias ramificações permitem a comunicação com outras células através da matriz; e osteoclatos, as vilosidades otimizam o processo de absorção de elementos exteriores ao proporcionar uma maior área de contato do osteoclatos com o tecido ósseo (JUNQUEIRA; CARNEIRO, 1996). 


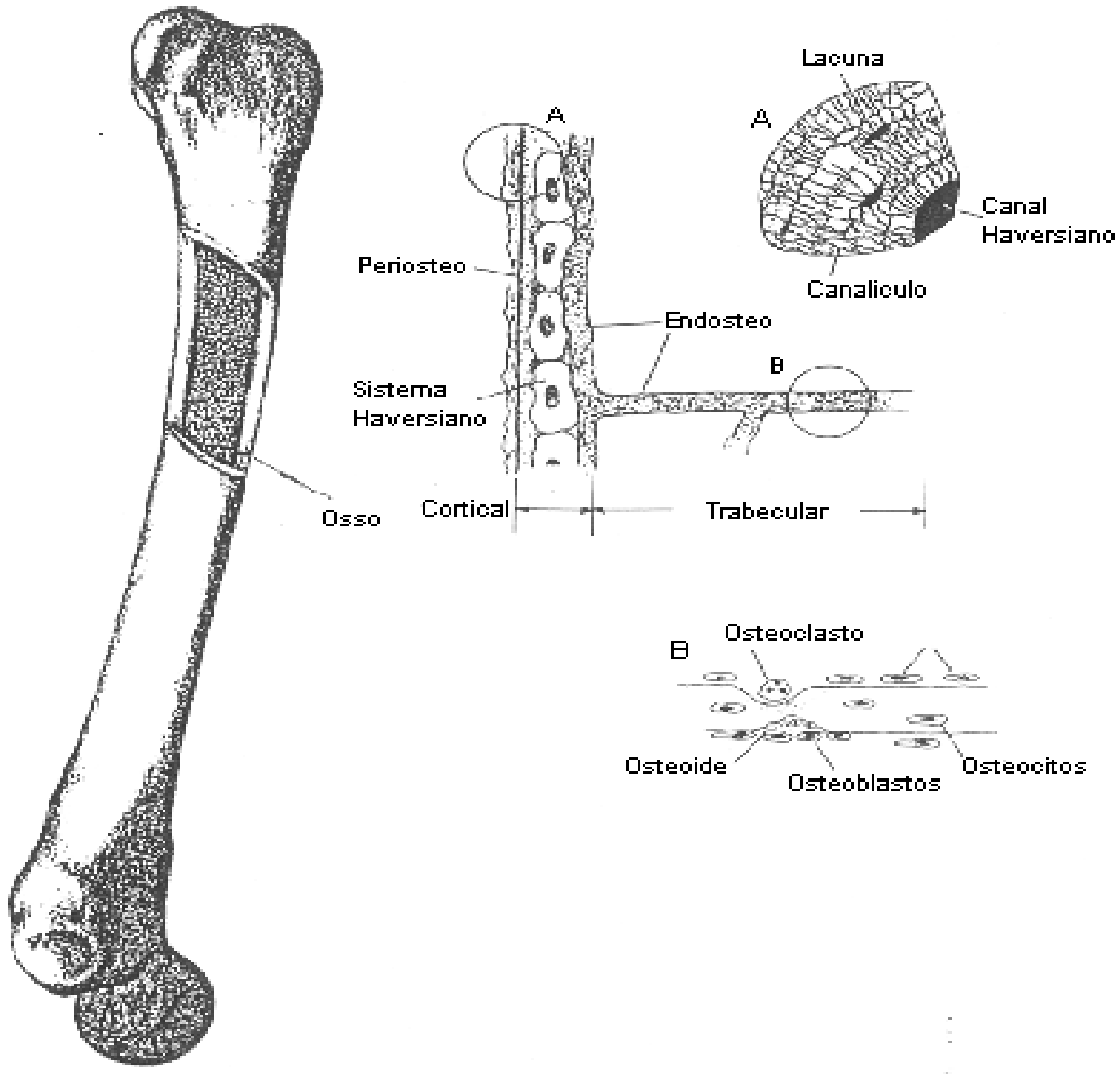

Fonte: Vilela (2007).

Figura 1 - (A) sistema haversiano, aparecem como anéis; periósteo, endósteo, (B) osteoblasto, osteócito e osteoclatos

De acordo com Junqueira e Carneiro (1995), os osteoblastos têm função de produzir a porção da matriz óssea, principalmente colágeno tipo I, proteoglicanas e glicoproteínas, possuindo ainda capacidade de sintetizar fosfatos de cálcio, os quais são utilizados na mineralização da matriz óssea (Figura 2). Osteócitos são osteoblastos já envolvidos pela matriz óssea e têm a função principal de permitir o fluxo de íons e hormônios no interior do tecido ósseo e realizar a manutenção da 
matriz óssea (Figura 3). Osteoclatos tem função de promover a remodelação dos tecidos ósseos através da reabsorção de elementos do tecido ósseo (Figura 4).

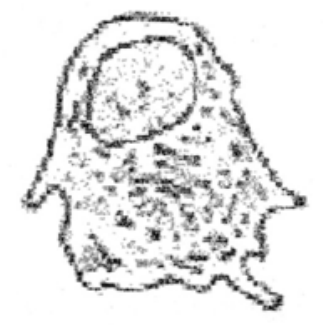

Fonte: Moure (2001)

Figura 2 - Osteoblasto. Presença de grande quantidade de organelas indica a característica de célula sintetizadora de substâncias

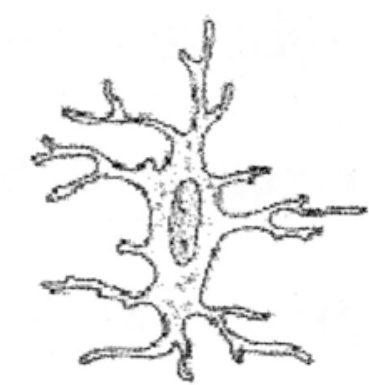

Fonte: Moure (2001).

Figura 3 - Osteócito. Ramificações estreitas permitem a comunicação com outras células através da matriz

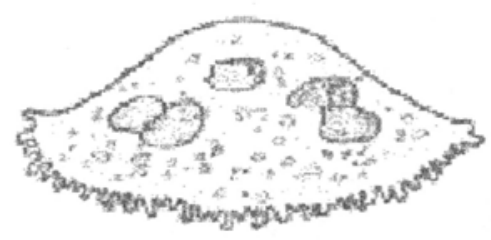

Fonte: Moure (2001).

Figura 4 - Osteoclasto. As vilosidades otimizam o processo de absorção de elementos exteriores ao proporcionar uma maior área de contato do osteoclasto com o tecido ósseo 
A matriz óssea pode ser dividida em duas partes, a orgânica e a inorgânica. A parte orgânica é constituída principalmente por fibras colágenas (95\%) e dá a forma ao tecido ósseo. Sobre as fibras colágenas são depositadas os componentes inorgânicos da matriz óssea, principalmente na forma de hidroxiapatita, e alguns outros íons como magnésio, potássio e sódio (MOURA, 2001).

A composição química do osso modifica-se durante o desenvolvimento embrionário, o crescimento pós-fetal e a maturação. O conteúdo mineral aumenta progressivamente à medida que o conteúdo de água diminui. A relação recíproca entre as frações de água e mineral sugere que, à medida que ocorre formação óssea, há substituição progressiva da água por mineral. A condensação da matriz óssea e seu elevado conteúdo mineral dificultam os processos de difusão, portanto, as células ósseas estão situadas bem próximas dos vasos sanguíneos, permitindo assim o acesso a nutrientes e ao oxigênio, e isto ocorre através dos condutos (canalículos) que penetram no tecido ósseo (WASSERMAN; KALLFELZ; GEORGE, 1996).

Existem dois tipos de tecido ósseo, o imaturo ou primário, e o maduro ou secundário. Ambos os tipos possuem as mesmas células e os mesmos constituintes na matriz óssea, mas enquanto no primário não existe uma organização espacial definida das fibras colágenas, o secundário apresenta essas fibras organizadas em lamelas. Devido a este fato o tecido secundário é referenciado também como tecido lamelar (MOURA, 2001).

O tecido primário possui teor menor de minerais do que o tecido secundário e é gradativamente substituído por este último à medida que o osso torna-se maduro. O sistema esquelético maduro é constituído quase exclusivamente de tecido ósseo secundário, estando o primário presente em apenas alguns pontos de inserção de tendões e nas suturas dos ossos do crânio (JUNQUEIRA; CARNEIRO, 1995).

O terceiro metacarpo dos eqüinos é um osso longo, com geometria bem definida, conforme demonstrado na figura 5. A escolha do terceiro metacarpo para o estudos que envolvem quantificação da matéria mineral óssea deve-se principalmente a três características dessa região: sua constituição é exclusivamente 
de osso cortical, a área transversal é aproximadamente constante e é uma região de fácil acesso, sem a presença de outros órgãos ou estrutura que possam atrapalhar o feixe de radiação (MOURA, 2001).

Região proximal

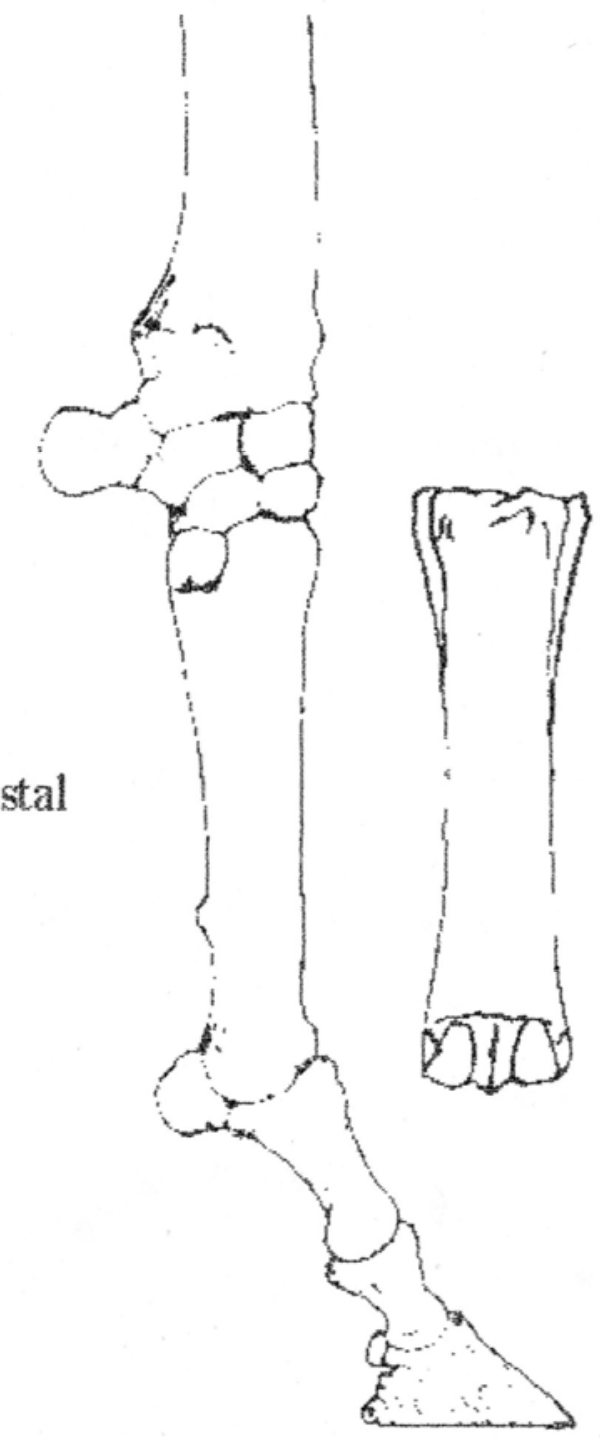

Fonte: Moure, (2001).

Figura 5 - Desenho esquemático da vista lateral e frontal do terceiro metacarpo de um eqüino, e sua localização no membro anterior 


\subsubsection{Morfologia dos ossos}

A forma do osso está intimamente ligada à função a que este se destina. Os ossos podem ser classificados em ossos longos, curtos ou chatos. Do ponto de vista macroscópico o osso pode ainda ser classificado como esponjoso (trabecular) ou compacto (cortical). Essa classificação surge do fato de existirem regiões de um mesmo osso que desempenham funções diferentes, o que acarreta diferenças na organização espacial do tecido ósseo. Do ponto de vista histológico não existem diferenças entre o osso esponjoso e o osso compacto (JUNQUEIRA; CARNEIRO, 1995).

O osso esponjoso possui cavidades intercomunicantes onde fica alojada a medula óssea, responsável principalmente pela produção de células do sangue. $O$ osso compacto não apresenta tais cavidades e uma conseqüência disso é que nos ossos esponjosos a área de contato entre tecidos ósseos e o sangue é significativamente maior do que nos ossos compactos. Esse é um dos motivos pelos quais os ossos esponjosos sofrem descalcificação mais rápido do que os ossos compactos (MOURA, 2001).

Os ossos curtos possuem o centro constituído de osso esponjoso, recoberto por uma camada de osso compacto. Os ossos chatos (como os ossos do crânio, por exemplo) assemelham-se a um sanduíche, em que duas placas de osso compacto são separadas por osso esponjoso. Os ossos longos, conforme ilustra a figura 6 , possuem osso esponjoso nas suas extremidades, epífeses, cobertas por uma camada de osso compacto. Entre as epífeses está localizada a diáfise, geralmente cilíndrica, e constituída de osso compacto. Principalmente nos ossos longos o osso compacto é chamado de osso cortical. O interior da diáfise, chamado de canal medular, é preenchido também pela medula óssea (JUNQUEIRA; CARNEIRO, 1995). 


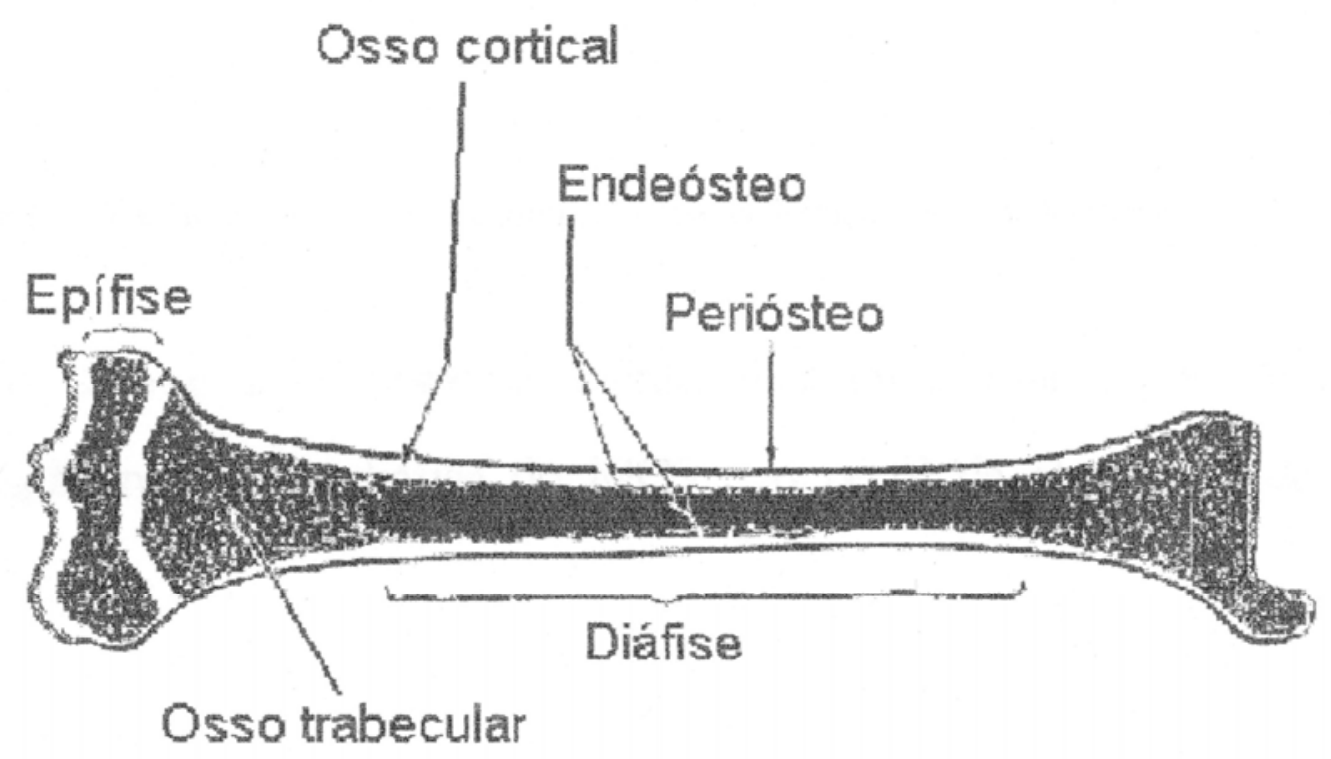

Fonte: Moure, (2001)

Figura 6 - Desenho esquemático de um osso longo, sendo visíveis as epífises (osso trabecular) e a diáfise (osso cortical), além de outras estruturas

\subsubsection{Modelagem e remodelagem óssea}

A remodelação é um fenômeno que acompanha os animais ao longo da vida, sendo fundamental para renovação do esqueleto e preservação de sua qualidade. Nele a reabsorção é seguida da formação óssea em ciclos constantes orquestrados pelas células do tecido ósseo, que incluem os osteoclastos, osteoblastos e osteócitos. Em situações fisiológicas normais, a reabsorção e a formação são fenômenos acoplados e dependentes, e o predomínio de um sobre o outro pode resultar em ganho ou perda de massa óssea (SARAIVA; CASTRO, 2002).

Por serem mineralizados, os ossos precisam ser remodelados para poder crescer. O crescimento dos ossos consiste na formação de tecido ósseo novo, associada à reabsorção parcial do tecido já formado. Dessa maneira, os ossos conseguem manter sua forma enquanto crescem (JUNQUEIRA; CARNEIRO, 1995). 
De acordo com Cadore, Brentano e Kruel (2005), a densidade mineral óssea (DMO) é o resultado de um processo dinâmico de formação e reabsorção do tecido ósseo chamado de remodelação. A reabsorção causa a deterioração desse tecido, enquanto a formação do mesmo é responsável pela reconstrução e fortalecimento do tecido deteriorado. Esse processo ocorre ao longo da vida em ciclos.

Ainda de acordo com os autores, a manutenção da DMO é muito importante para a prevenção da osteoporose, caracterizada por diminuição acentuada da DMO, no qual a matriz e os minerais ósseos são perdidos devido ao excesso de reabsorção óssea em relação à formação. Esse processo é normalmente associado ao avanço da idade e à ocorrência da menopausa e leva a maior incidência de fraturas.

Segundo Wasserman, Kallfelz e George (1996), a formação do osso novo ocorre de forma coordenada nas suas superfícies externas e a reabsorção óssea nas superfícies internas. O crescimento do osso não é uma simples questão de deposição de mais matriz à superfície externa, pois desta forma, o osso de um individuo adulto seria extremamente pesado e a cavidade medular seria inaceitavelmente pequena.

A atividade destrutiva dos osteoclastos e construtiva dos osteoblastos possibilita a remodelação dos ossos. Apesar de sua resistência às pressões e da dureza, o tecido ósseo é muito plástico, sendo capaz de remodelar sua estrutura interna em resposta a modificações nas forças a que está submetido normalmente (JUNQUEIRA; CARNEIRO, 1995).

Numerosos estudos indicam que a atividade física está positivamente relacionada com a DMO, sendo um importante fator na sua manutenção. Alguns estudos relacionam os efeitos de diversas modalidades esportivas na DMO de atletas ou indivíduos fisicamente ativos. Entre esses estudos, alguns utilizam o treinamento de força como intervenção, na tentativa de aumentar a DMO de indivíduos submetidos a esse tipo de atividade física. Geralmente, os mesmos estudos têm mostrado resultados positivos em relação à DMO. Entretanto, apesar desse possível efeito benéfico, volumes muito grandes de treinamento podem ser 
prejudiciais à DMO. Esse prejuízo parece ter estreita relação com a perturbação da homeostase hormonal do organismo (CADORE; BRENTANO; KRUEL, 2005).

\subsubsection{Reabsorção óssea}

De acordo com Wasserman, Kallfelz e George (1996), o processo de reabsorção óssea é caracterizado pela dissolução da matriz do osso através da atuação das células ósseas. Tanto os constituintes orgânicos solúveis e insolúveis da matriz precisam ser degradados e solubilizados. Os produtos (peptídeos e aminoácidos das proteínas ósseas e os íons minerais) são transferidos para a circulação sistêmica. Os osteoclastos são os principais responsáveis pelo processo de reabsorção óssea, mas os osteoblastos podem estar envolvidos neste processo, apesar de ser tradicionalmente exclusivo na formação óssea.

\subsection{Cálcio e Fósforo}

O Cálcio e o Fósforo compreendem cerca de $70 \%$ do conteúdo mineral do corpo e 30 a 50\% dos minerais do leite. A grande maioria do Cálcio orgânico (99\%) está localizada nos ossos e dentes, sendo o primeiro deles o órgão de reserva do elemento. O Cálcio ionizado constitui normalmente cerca da metade do Cálcio plasmático total. Cerca de $40 \%$ do Cálcio plasmático se conjuga primariamente com a albumina; os restantes 10 a $15 \%$ se conjugam primeiramente com o citrato, nitrato e sulfato (LEWIS, 2000).

Além desta função estrutural, o Cálcio está diretamente ligado à contração muscular através do controle da liberação de adenosina tri-fosfato (ATP) no sistema actina-miosina. O Cálcio também regula a contração da musculatura cardíaca e lisa, 
controla indiretamente a passagem de estímulos nervosos pelo neurônio e a passagem do impulso nervoso pela placa neuromuscular através da liberação de acetilcolina. Este elemento também está relacionado com a coagulação sanguínea, produção láctea e da casca do ovo (ORTOLANI, 1996).

O Cálcio dos ossos está em intercâmbio constante com o Cálcio dos líquidos extracelulares. O esqueleto contém $99 \%$ do Cálcio do organismo e funciona como reservatório deste íon, cuja concentração no sangue (calcemia) e nos tecidos deve ser mantida constante. Há intercâmbio contínuo entre o Cálcio do plasma sanguíneo e dos ossos. O Cálcio absorvido da alimentação e que faria aumentar a concentração sanguínea deste íon é depositado rapidamente no tecido ósseo e, inversamente, o Cálcio dos ossos é mobilizado quando diminui sua concentração no sangue (JUNQUEIRA; CARNEIRO, 1995).

Para Nielsen et al. (1998a), a dinâmica da troca que ocorre no sistema esquelético em eqüinos jovens põe em dúvida a quantidade necessária de minerais durante o período crítico de crescimento e treinamento. Desta forma, os eqüinos jovens podem estar recebendo dietas com quantidades deficientes em Cálcio, como também outros minerais. Durante o início do treinamento, quantidade significativa de Cálcio é retirada dos ossos, pois nessa fase de estresse qualquer osso do corpo pode sofre remodelação. E quando o consumo de Cálcio não é adequado para as funções corporais, muitas mudanças ocorrem na tentativa de manter a homeostase de Cálcio, dessa maneira o desbalanço faz com que o organismo remova o Cálcio dos ossos, resultando em completo enfraquecimento do sistema esquelético.

Existe um mecanismo duplo de mobilização do Cálcio depositado nos ossos. O primeiro é representado pela simples transferência dos íons dos cristais de hidroxiapatita para o líquido intersticial, do qual o Cálcio passa para o sangue. Esse mecanismo é puramente físico e tem lugar principalmente no osso esponjoso. As lamelas ósseas mais jovens, pouco calcificadas, que existem mesmo no osso adulto, devido à remodelação contínua, são as que recebem e cedem Cálcio com maior facilidade. O segundo mecanismo da mobilização do Cálcio é de ação mais lenta e decorre da ação do hormônio da paratireóide ou paratormônio sobre o tecido ósseo. Este hormônio causa aumento no número de osteoclastos e reabsorção da matriz 
óssea, com liberação de fosfato de cálcio e aumento da calcemia (JUNQUEIRA; CARNEIRO, 1995).

De acordo com as recomendações do NRC (2007), estimam-se, para potros em crescimento, perdas endógenas de Cálcio de $20 \mathrm{mg} / \mathrm{kg}$ de peso corporal por dia e deposição de aproximadamente $16 \mathrm{~g}$ de Cálcio/kg de peso corporal. Portanto, para um potro com $215 \mathrm{~kg}$, ganho de $0,85 \mathrm{~kg} /$ dia e que apresente absorção eficiente de $50 \%$, o requerimento de Cálcio dietético é de $27,2 \mathrm{~g} / \mathrm{dia}(16 \mathrm{~g} \times 0,85 \mathrm{~kg} / 0,5)$ para crescimento do esqueleto. Além disso, um acréscimo de mais $8,6 \mathrm{~g} / \mathrm{dia}(215 \mathrm{~kg} x$ $20 \mathrm{mg} / 0,5)$ devido às perdas endógenas, sendo assim, um requerimento de $35,8 \mathrm{~g}$ de Cálcio/dia.

Como o Cálcio, cerca de $80 \%$ do Fósforo do corpo encontra-se nos ossos e dentes. O Fósforo é necessário como tampão para o metabolismo energético e para várias outras funções celulares (LEWIS, 2000).

O Fósforo participa da estrutura bioquímica de grande número de moléculas, como os fosfolipídeos responsáveis pela metabolização de gorduras e enzimas. Outra função importante é a conservação e captura de energia no sistema biológico, armazenada sob a forma de ATP e gerada através da fosforilação oxidativa na cadeia respiratória dentro da mitocôndria (ORTOLANI, 1996).

Segundo O NRC (2007), estima-se para potros em crescimento uma deposição aproximada de $8 \mathrm{~g}$ de Fósforo/kg de peso corporal e perdas endógenas de Fósforo de $10 \mathrm{mg} / \mathrm{kg}$ peso corporal por dia. Portanto um potro com $215 \mathrm{~kg}$ e absorção eficiente de Fósforo de $45 \%$, com ganho de peso de $0,85 \mathrm{~kg} / \mathrm{dia}$, precisará de aproximadamente $15,1 \mathrm{~g}$ de Fósforo $(8 \mathrm{~g} \times 0,85 \mathrm{~kg} / 0,45)$, além da exigência de $4,8 \mathrm{~g}$ para manutenção $(215 \mathrm{~kg} \times 10 \mathrm{mg} / 0,45)$. Assim, é necessária uma suplementação de $20 \mathrm{~g}$ de Fósforo/dia (NRC, 2007).

Ott e Asquith (1989), objetivando determinar qual ponto ótimo de ingestão de microminerais influenciariam o crescimento e desenvolvimento do esqueleto em eqüinos, evidenciaram que ingestão deficiente de microminerais reduz a mineralização óssea de cavalos jovens e que a suplementação de microminerais não altera o requerimento de Cálcio e Fósforo do animal. 
Conforme relata Wolter (1992) um desbalanço na relação Ca/P prejudica a absorção de Cálcio, Magnésio e microelementos como o Zinco, mas o Fósforo continua sendo assimilado. Isto induz uma hiperfosforose que desencadeia uma hiperfosfatemia, levando ao aparecimento de hiperparatireoidismo que, ao final, causará desmineralização óssea.

De acordo com Jackson e Pagan (1993) a aplicação inadequada de complementos alimentares que não respeitam as necessidades nutricionais, que variam para cada raça, estado fisiológico e o tipo de atividade física do animal, pode desencadear o surgimento de problemas osteoarticulares e tendinosos. Tanto as carências e desequilíbrios nutricionais, como o excesso de nutrientes ou nutrição desbalanceada geram as principais doenças ortopédicas.

Jackson e Pagan (1993) também relataram que a causa mais provável da ocorrência das OCD é uma deficiência ou desbalanço mineral.

Conforme Lawrence et al. (1994) relataram que a quantidade de minerais contidos nos ossos pode influenciar na resistência do esqueleto a injúrias. Em um estudo post-mortem do metacarpo de eqüinos a quantidade de minerais contidos no osso foi altamente correlacionada com força, elasticidade e carga para quebrar o osso, e essas características influenciaram a resistência mecânica a injúrias.

A dieta e o exercício são dois fatores de manejo que afetam a densidade e força óssea. Porr et al. (1998) propuseram que a densidade e a quantidade de Cálcio nos ossos são afetadas pelo descondicionamento ao exercício por 12 semanas e pela concentração de Cálcio na dieta. Os resultados encontrados revelaram que durante o descondicionamento, a quantidade de minerais no osso diminui aproximadamente $1,1 \mathrm{~g} / \mathrm{cm}^{2}$ ou $0,45 \%$ por semana. Esta diminuição não foi afetada pela dieta de Cálcio. A concentração sérica de Cálcio aumentou com o descondicionamento. Os resultados sugerem que dietas com duas vezes mais a quantidade de Cálcio recomendada pelo NRC (1989) não recuperam a perda na quantidade de minerais nos ossos em resposta ao descondicionamento.

Nielsen et al. (1998a) descreram aumento no metabolismo ósseo no início de treinamento de cavalos jovens. A quantidade de minerais no metacarpo diminuiu quando o processo de remodelação óssea iniciou. Isso foi evidenciado por 
decréscimo inicial em radiografias com densitometria óssea. Houve aumento da concentração de Ca e P sérico liberado do osso para a circulação. Adicionalmente, ocorreu diminuição da quantidade de minerais no metacarpo, diminuição da ação osteoblástica e desta maneira ocorreu diminuição da formação óssea.

Nielsen et al. (1998b) estudando o efeito da suplementação mineral em potros que entram cedo em treinamento, utilizaram tratamentos com $28,3 \mathrm{~g} \mathrm{Ca} / \mathrm{dia}$ e $21,9 \mathrm{~g}$ P/dia para um grupo e 34,9 g Ca/dia e 26,4 g P/dia para o outro, observaram que o grupo que recebeu dieta com maior quantidade de $\mathrm{Ca}$ teve maior retenção mineral e melhor formação óssea, concluindo que o aumento da retenção de Ca foi benéfico e facilitou o processo de remodelação óssea e, conseqüentemente, o crescimento do esqueleto quando comparado ao controle.

Bell et al. (2001) descreveram que o osso, principalmente na fase de crescimento, adapta-se de acordo com a força exposta, alterando sua massa e arquitetura. Aumentando-se a carga com o exercício, aumenta-se a massa óssea, do mesmo modo que quando a carga é diminuída a massa do osso também diminui. $O$ crescimento ósseo em potros é rápido, e alterações durante o desenvolvimento podem ter grande impacto na qualidade do osso na vida adulta.

Buchholz-bryant et al. (2001) demonstraram o efeito da suplementação de Cálcio e Fósforo em eqüinos em inatividade em subseqüente atividade anaeróbia crescente trabalhando com cavalos jovens, adultos e velhos e utilizando dietas com $133 \%$ e $275 \%$ das recomendadas de Ca e $P$, respectivamente, feitas pelo NRC (1989). Observaram aumento no balanço de Ca no início do período de exercício seguido por um período de sedentarismo, que pode indicar maior quantidade de mineral disponível para remodelação, sugerindo ser benéfica uma quantidade adicional de Ca e P na dieta. Relataram, também, que as dietas contendo $275 \%$ de Ca e $\mathrm{P}$ acima das recomendações do NRC resultaram em retenção de Ca que altera a reabsorção e o processo de remodelação óssea em cavalos em diferentes idades. Concluíram que cavalos adultos e velhos são beneficiados com o aumento de Ca na dieta, mas são os cavalos jovens que apresentam maior necessidade com o início do exercício. 
De acordo com Wasserman, Kallfelz e George (1996), as concentrações de Ca e $\mathrm{P}$ no sangue e no líquido extracelular que banham as superfícies ósseas são determinantes importantes da mineralização. Se as concentrações desses íons nos fluidos corporais estiverem baixas, a mineralização não ocorre, ou ocorre em ritmo lento.

\subsection{Minerais quelatados}

A absorção dos minerais presentes numa mistura depende, em parte, da interrelação existente entre eles, dado que os cátions dos sais minerais inorgânicos dissolvidos no sistema digestivo do animal são expostos à influência da camada externa de elétrons de outros minerais ionizados (CAZES; SOARES, 2004).

Isto resulta numa competição que interfere na absorção dos minerais presentes no trato digestivo. Esses efeitos negativos dos minerais inorgânicos ionizáveis no sistema digestivo podem ser eliminados pelo uso de minerais na forma de quelatos, que, por estarem ligados quimicamente a um composto orgânico não ionizável no sistema digestivo, quando bem preparados, não apresentam antagonismos e nem formação de compostos insolúveis (CAZES; SOARES, 2004).

De acordo com Chitolina e Glória (1990) a definição de complexo é, de maneira geral, todo composto contendo um íon ou átomo metálico ao qual se acham ligados por covalência de coordenação outros íons ou moléculas. Os íons ou moléculas ligadas ao átomo metálico central são denominados ligantes. Para atuarem como ligantes, os íons ou moléculas devem possuir par ou pares de elétrons não compartilhados, que estabelecem as ligações coordenadas.

Conhecem-se também complexos que contém dois ou mais átomos metálicos unidos entre si por um ou mais ligantes que funcionam como ponte. São chamados complexos polinucleares. Os ligantes ligam-se ao átomo metálico central por apenas um único ponto, ou seja, uma única ligação para cada ligante-átomo central. Já nos quelatos alguns ligantes podem ser ligados ao átomo metálico central por mais de 
um ponto de ligação. Em outras palavras, um mesmo ligante pode ocupar mais de uma posição de coordenação. Os complexos desse tipo são chamados quelatos e os ligantes agentes quelantes ou ligantes de quelação (CHITOLINA; GLÓRIA, 1990).

Segundo a Association of American Feed Control Officials (2004) produtos minerais orgânicos são definidos como:

- Metal aminoácido quelato é um produto resultante da reação de um íon metálico de sal solúvel com aminoácidos na relação de um mol de metal com um a três (de preferência dois) moles de aminoácidos de forma coordenada com ligações covalentes. Com o peso médio de hidrolise aproximado 150 e o peso molecular do quelato não pode exceder 800 moles.

- Complexos aminoácido-metal é um produto resultante da complexação de um sal metálico solúvel com um ou mais aminoácidos.

- Metal proteinado é o produto resultante da quelação de um sal solúvel com uma proteína parcialmente hidrolisada.

- Complexo metal polissacarídeo é o produto resultante da complexação de um sal solúvel com polissacarídeo.

A palavra quelato vem do grego "chele" que significa garra. Souza; Boin, (2002) denominaram minerais quelatados como compostos formados por íons metálicos ligados a aminoácidos, peptídeos ou complexos polissacarídeos que proporcionam a esses íons alta biodisponibilidade biológica, estabilidade e solubilidade.

2.4 Biodisponibilidade e absorção dos quelatos

Estudos recentes têm desenvolvido compostos orgânicos semelhantes àquelas moléculas responsáveis pelo transporte de minerais no organismo animal. Sendo assim, a biodisponibilidade, que é considerada uma medida de habilidade de um mineral em sustentar processos biológicos que ocorrem nos animais, é 
dependente de três condições básicas na estrutura do composto (SOUZA; BOIN, 2002):

- Forma de ligação com o metal: nos quelatos formados com dois ou três aminoácidos, o íon metálico fica inerte na molécula, entrando com facilidade nas vias metabólicas, pois assume a característica da molécula orgânica.

- Peso molecular da forma quelatada: o baixo peso molecular é a chave para absorção como uma molécula intacta. Se o peso molecular de um quelato for maior que 800 moles, certamente sofrerá prévia hidrólise na luz do trato digestivo e a absorção pela mucosa não será garantida.

- Constante de estabilização do quelato: deve ser constituído de dois ou três anéis de aminoácidos quelantes para serem estáveis. Se a constante de estabilização dos aminoácidos é grande, estes irão resistir à ação das peptidases que quebram as ligações peptídicas internas, liberando o átomo de metal na molécula.

A constante de estabilização do quelato, segundo Chitolina e Glória (1990) é a estabilidade dos complexos, determinada pela energia de ligação entre o metal e o ligante. Ela é caracterizada quantitativamente pelas constantes que descrevem o equilíbrio dos complexos. Esta classe de compostos orgânicos forma complexos estáveis, solúveis em água com muitos cátions metálicos.

Muitos agentes complexantes e quelantes são bases de Lewis (capazes de doar par de elétrons) e também bases de Brönsted (capazes de receber prótons) e, conseqüentemente, são afetadas pelas mudanças no pH (CHITOLINA; GLÓRIA, 1990).

Minerais na forma inorgânica são geralmente ionizados no estômago e posteriormente absorvidos no intestino delgado, onde $\mathrm{o} \mathrm{pH}$ ácido determina a solubilidade. Nesse local se ligam a proteínas e posteriormente são incorporados pela membrana das células da mucosa intestinal. A passagem para o interior das células poderá ocorrer por difusão passiva ou transporte ativo. Nessas condições podem ocorrer perdas através da formação de compostos como colóides insolúveis ou competição pelos sítios de absorção entre os elementos minerais, com interações antagônicas que inibem a absorção (SOUZA; BOIN, 2002). 
Segundo Rompala e Halley (1995), os quelatos melhoram a absorção do mineral no trato digestivo provavelmente porque são mais solúveis e podem atravessar a parede intestinal mais facilmente.

Vandergrift (1993) relatou melhora do sistema imune em dietas contendo microminerais quelatados, visto que estes nutrientes são requeridos para inúmeras funções do próprio sistema, e, devido à melhor disponibilidade dos minerais na forma quelato, há melhora na função imune.

Ott e Johnson (2001), comparando o efeito de microminerais orgânicos com inorgânicos, observaram que houve diferenças significativas entre os tratamentos quanto à altura dos animais e o crescimento dos cascos, sendo tais parâmetros maiores para os animais que receberam dietas com microminerais orgânicos. Porém, nenhuma diferença entre os tratamentos foi observada quanto ao ganho de peso.

Ley et al. (1990) relataram que éguas que receberam suplementação combinada de microminerais orgânicos e inorgânicos tiveram tendência para a redução do número de inseminações. Porém, Ott e Asquith (1994) não evidenciaram diferenças no desempenho reprodutivo no que diz respeito à redução do tempo do primeiro cio e redução do número de trabalhos por égua.

\subsection{Avaliação do desenvolvimento de eqüinos}

Proporções, na avaliação do desenvolvimento dos animais, são as relações entre as diversas regiões do corpo e o conjunto formado por elas. O eqüino é considerado bem proporcionado se as partes do corpo, observadas em conjunto, são adaptadas à função a que ele se destina, como sela, esporte ou tração (CABRAL et al., 2004).

As proporções corporais podem ser avaliadas a partir de índices que evidenciem relações entre as medidas de comprimento, de perímetro e de peso (OOM; FERREIRA, 1987). O Sistema Eclético de Proporções Lineares, proposto por Lesbre (1920) e citado por Cabral et al. (2004), tem sido utilizado há várias décadas 
no estudo das proporções de cavalos de sela. Baseia-se no comprimento da cabeça e apresenta as seguintes relações, entre outras: a altura da cernelha e da garupa e o comprimento do corpo equivalem a duas vezes e meia o comprimento da cabeça, assim como o comprimento do pescoço e das espáduas apresentam o mesmo valor do comprimento da cabeça.

Num estudo realizado por Willoughby (1975) citado por Cabral et al. (2004), foram analisadas as proporções do comprimento do corpo em relação à altura da cernelha, em eqüinos da raça Quarto de Milha, e encontrados valores de 76 e 76,2\%, ao nascimento, e de 106,7 e 107,6\%, à idade adulta, nos machos e nas fêmeas, respectivamente. Segundo Cabra et al. (2004), ao nascimento, os potros da raça PSI são mais altos que compridos, mantendo-se esta estrutura até um ano de idade, quando o comprimento do corpo começa a aumentar rapidamente, igualando-se à medida de altura entre os dois e três anos de idade e chegando à idade adulta 5 a 10 cm maior que a altura na cernelha.

Ainda de acordo com Cabral et al. (2004), o cavalo Mangalarga Marchador pode ser considerado um eqüino eumétrico - tem volume e pesos medianos, variando de 350 a $500 \mathrm{~kg}$ - e também mesomorfo - possui medidas longitudinais e verticais equilibradas com as transversais, apresentando proporcionalidade nas linhas das regiões do corpo. 


\section{MATERIAL E MÉTODOS}

Os materiais e as metodologias utilizados neste trabalho estão descritos nos itens que se seguem.

3.1 Local e animais

O experimento foi conduzido na Universidade de São Paulo, nas instalações do Setor de Eqüideocultura da Faculdade de Medicina Veterinária e Zootecnia, Campus Administrativo de Pirassununga, situado no município de Pirassununga/SP.

Foram utilizados dez potros com peso aproximado de $221 \mathrm{~kg}$ e idade entre 10 e 13 meses, vacinados contra tétano, vermifugados e pulverizados contra ectoparasitos. Os animais foram alojados em baias individuais com 3,5 metros de comprimento, e 3,5 metros de largura e piso de concreto forrado com maravalha.

\subsection{Dieta}

O concentrado foi fornecido na quantidade de $2,5 \%$ do peso vivo dos potros, com o objetivo de atender as exigências do NRC (1989) para a categoria. A relação de concentrado/volumoso fornecida foi de 60:40, divididos igualmente em duas refeições ao dia. O volumoso era fornecido às 7:00 e às 15:00h, e o concentrado, às 9:00 e às 17:00h.

Foram realizadas análises bromatológicas dos componentes da dieta (AOAC, 1995), volumoso de feno de Tifton (Cynodon sp) e do concentrado, cujos ingredientes e quantidades utilizadas estão descritos da tabelas 1 e 2. 
Tabela 1 - Quantidades em porcentagem de ingredientes utilizados na formulação do concentrado - Pirassununga - SP - 2006

\begin{tabular}{lc}
\hline Ingredientes & Concentrado \\
\hline Aveia grão & 12,0 \\
Melaço em pó & 3,7 \\
Milho extrusado & 51,0 \\
Farelo de soja & 3,0 \\
Soja extrusada & 30,0 \\
Calcita & 0,3 \\
\hline
\end{tabular}

Tabela 2 - Composição bromatologica dos componentes utilizados na dieta - Pirassununga - SP 2006

\begin{tabular}{lcc}
\hline Composição bromatológica & Concentrado & Volumoso \\
\hline MS (\%) & 92,08 & 89,7 \\
ED (mcal/kg) & 3,33 & 2,74 \\
PB (\%) & 14,26 & 12,84 \\
Ca (\%) & 0,24 & 0,35 \\
P (\%) & 0,22 & 0,16 \\
FB (\%) & 3,53 & 28,57 \\
FDN (\%) & 7,42 & 86,12 \\
EE (\%) & 5,88 & 2,37 \\
\hline
\end{tabular}

${ }^{1}$ A energia digestível mcal/kg foi calculada pelo NRC (1989).

Foi adicionada ao concentrado, quando este já estava disponível aos animais no cocho, a mistura mineral orgânica ou inorgânica na quantidade de $3 \%$. A composição das misturas minerais orgânico e inorgânico, os níveis de garantia estão apresentados nas tabelas 3 e 4 . 
Tabela 3 - Ingredientes utilizados na formulação das misturas minerais orgânicas e inorgânicas com os mesmo níveis de garantia - São Paulo - SP - 2006

\begin{tabular}{lcc}
\hline Ingredientes & Orgânico \% & Inorgânico \% \\
\hline Carbonato de Cálcio & 9,74 & 8,83 \\
Fosfato bicálcico & 38,462 & 38,46 \\
Cloreto de sódio & 1,0 & 0,286 \\
Carboquelato de cobre & & \\
Sulfato de cobre & 3,7 & 1,0 \\
Carboquelato de zinco & & \\
Sulfato de zinco & 0,01 & 0,014 \\
Carboquelato de cobalto & & \\
Sulfato de cobalto & 2,0 & 0,69 \\
Carboquelato de manganês & & 0,015 \\
Sulfato de manganês & 0,015 & \\
lodato de cálcio & 0,011 & 0,047 \\
Carboquelato de selênio & & \\
Selenito de sódio & 5,0 & 0,23 \\
Carboquelato de enxofre & & \\
Enxofre & 2,0 & \\
Carboquelato de ferro & 40 & \\
Carboquelato de cálcio & 5 , & \\
\hline
\end{tabular}

* análise realizada pela empresa Tortuga Cia. Zootécnica Agrária 
Tabela 4 - Composição das misturas minerais orgânicas e inorgânicas - São Paulo - SP - 2006

\begin{tabular}{lcc}
\hline Níveis de Garantia & Orgânico & Inorgânico \\
\hline Cálcio \% & 13 & 13 \\
Fósforo \% & 7,5 & 7,5 \\
Zinco mg/kg & 3,700 & 3,500 \\
Cobre mg/kg & 1,000 & 1,000 \\
Manganês mg/kg & 2,000 & 2,000 \\
lodo mg/kg & 90,28 & 90,28 \\
Cobalto mg/kg & 14 & 14 \\
Selênio mg/kg & 11 & 11 \\
Sódio \% & 15 & 15 \\
Cloro \% & 23,07 & 23,07 \\
Enxofre \% & 0,5 & 0,5 \\
Ferro mg/kg & 2,238 & 2,570 \\
\hline
\end{tabular}

* análise realizada pela empresa Tortuga Cia. Zootécnica Agrária

\subsection{Tratamentos}

Foram realizados dois tratamentos no experimento: $T$ (tratamento) - mistura mineral orgânica; C (controle) - mistura mineral inorgânica, com cinco repetições por tratamento. As duplas para cada tratamento foram formadas a cada mês, quando os animais completavam 10 meses de idade. Aleatoriamente, um animal seguia para o T e o outro para o $\mathrm{C}$, permanecendo assim até o fim da fase de coleta de amostra, com duração de 90 dias.

O sal mineral do $\mathrm{T}$ foi composto por ingredientes na forma de carboquelato $\mathrm{e}$ do C, por sulfatos. 
Tabela 5 - Formação das duplas, distribuição nos tratamento de acordo com a idade dos animais e consequentemente datas de inicio e termino do experimento - Pirassununga - SP - 2006

\begin{tabular}{ccccc}
\hline Nome & Dupla & Sal mineral & Inicio & Término \\
\hline Xuvisco & A & Inorgânico & $05 / 09 / 2005$ & $05 / 12 / 2005$ \\
Xaxado & A & Orgânico & $05 / 09 / 2005$ & $05 / 12 / 2005$ \\
Xarmosa & B & Inorgânico & $05 / 10 / 2005$ & $05 / 01 / 2006$ \\
Xilena & B & Orgânico & $05 / 10 / 2005$ & $05 / 01 / 2006$ \\
Xamego & C & Inorgânico & $05 / 10 / 2005$ & $05 / 01 / 2006$ \\
Xaveco & C & Orgânico & $05 / 10 / 2005$ & $05 / 01 / 2006$ \\
Xadrez & D & Orgânico & $04 / 11 / 2005$ & $06 / 02 / 2006$ \\
Xena & D & Inorgânico & $04 / 11 / 2005$ & $06 / 02 / 2006$ \\
Xacal & E & Inorgânico & $05 / 12 / 2005$ & $06 / 03 / 2006$ \\
Xonada & E & Orgânico & $05 / 12 / 2005$ & $06 / 03 / 2006$ \\
\hline
\end{tabular}

3.4 Avaliação de desenvolvimento

Para avaliação do desenvolvimento dos potros, foram mensuradas a cada 15 dias as alturas da cernelha e da garupa, o perímetro torácico, do joelho e da canela, conforme descrito por Cabral et al. (2004).

Os animais foram submetidos às mensurações sempre no mesmo local, em solo plano, contidos por cabresto. As medidas foram tomadas sempre no membro torácico esquerdo (Figuras 7 e 8). 


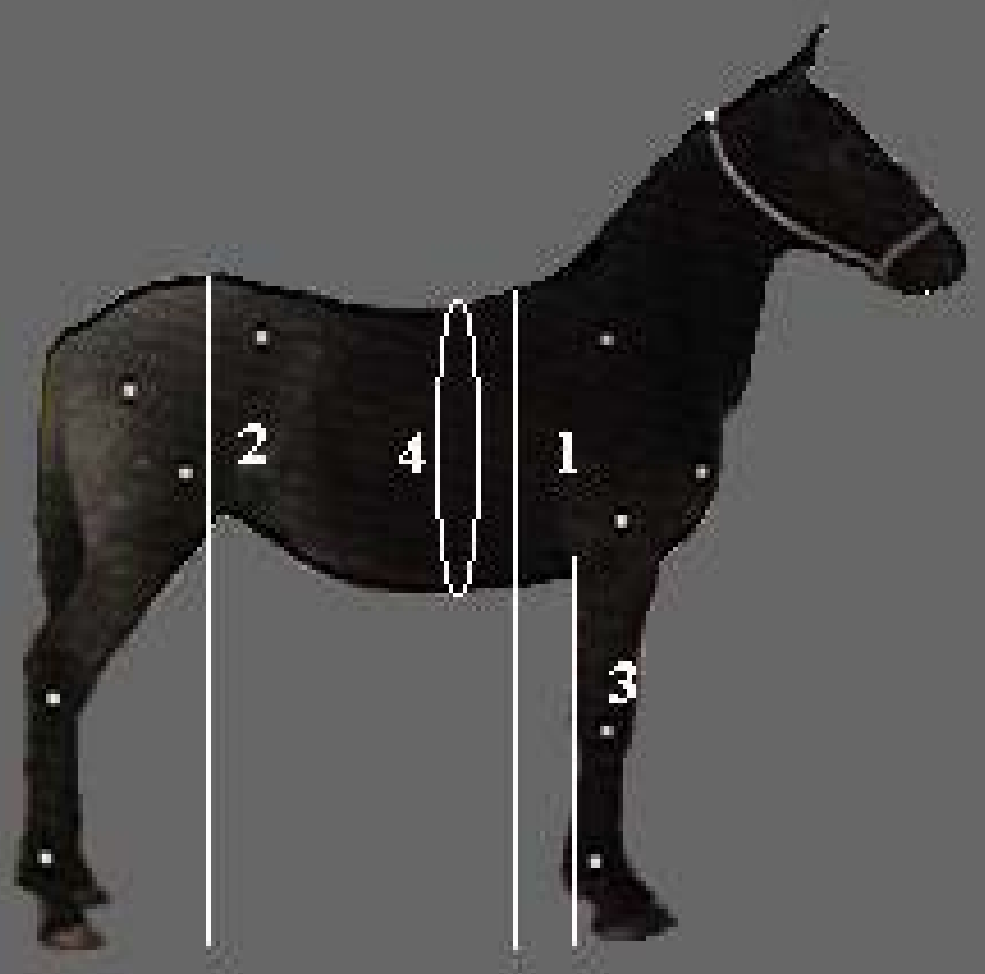

Fonte: Cabral et al. (2004)

Figura 7 - Medidas de altura da cernelha (1) e da garupa (2), distância codilho-solo (3) e perímetro torácico (4) 


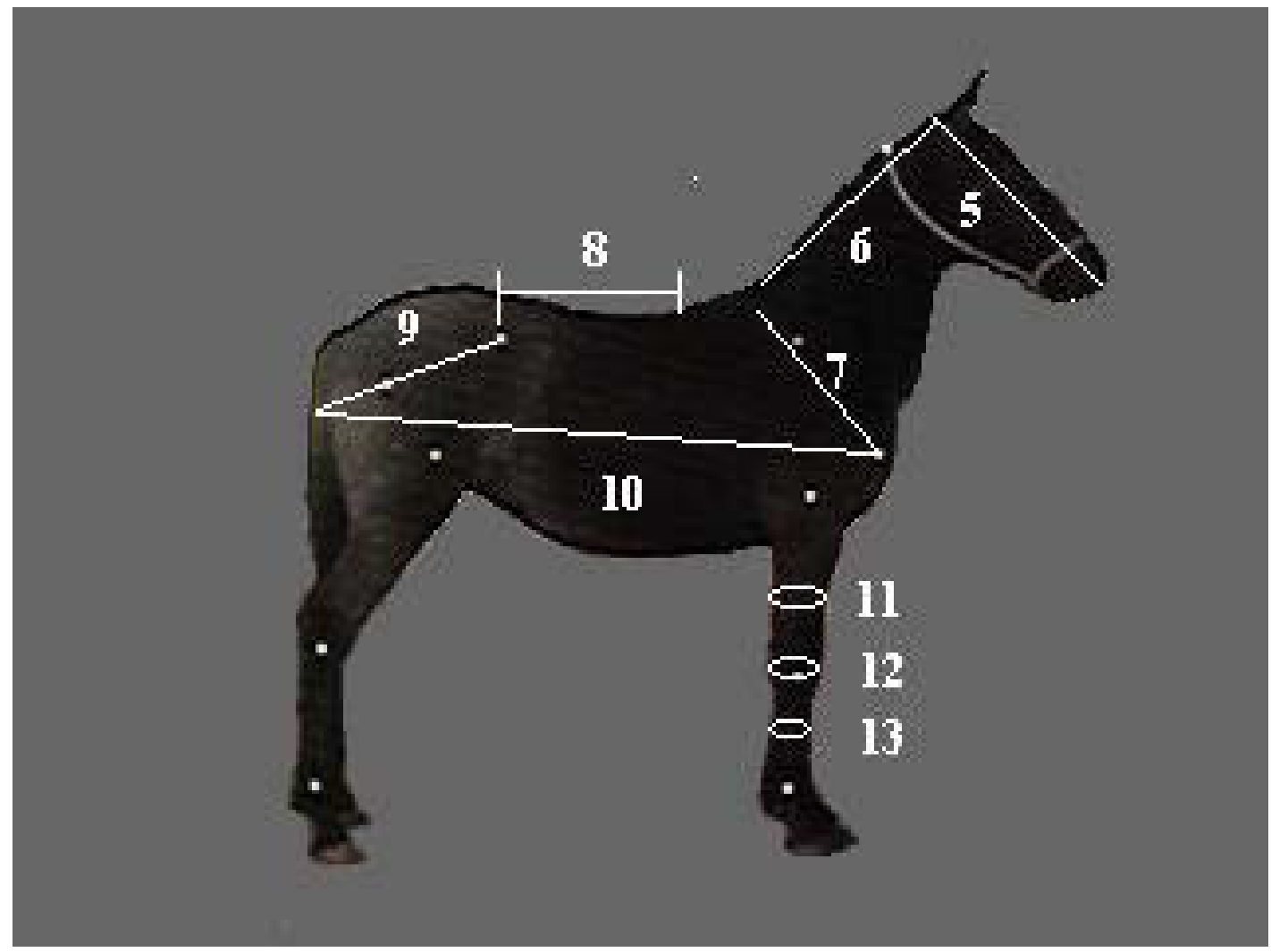

Fonte: Cabral et al. (2004).

Figura 8 - Medidas de comprimento da cabeça (5), do pescoço (6), da espádua (7), do dorsolombo (8), da garupa (9) e do corpo (10), e perímetros do antebraço (11), joelho (12) e canela (13)

- Altura da cernelha: Medida tomada do solo até o ponto mais alto da cernelha, estando a haste do hipômetro apoiada sobre as extremidades livres do quinto ou sexto processo espinhoso torácico, que representa o ponto mais alto da cernelha. A haste faz um ângulo de 90 graus com o corpo da bengala, que se projetou perpendicularmente até o solo.

- Altura da garupa: Medida tomada do solo até o ponto mais alto da transição lombo sacro, com a haste horizontal do hipômetro colocada sobre a extremidade sacral do ílio, estando o corpo da bengala projetado perpendicularmente ao solo.

- Perímetro do joelho: Medida tomada com uma fita métrica no local de maior diâmetro da articulação do carpo, tomando o cuidado de deixar a fita paralela ao solo. 
- Perímetro da canela: Medida tomada com uma fita métrica no local de maior diâmetro do metacarpo, tomando o cuidado de deixar a fita paralela ao solo.

- Perímetro torácico: Medida tomada circundando o tórax com uma fita métrica passada imediatamente após a cernelha.

\subsection{Biopsia óssea}

Foram realizadas 04 biopsias por animal no túber sacral do ílio, na porção onde o osso se encontra mais exposto, sendo realizadas a cada 30 dias, alternando os lados (direito e esquerdo) a cada mês.

Previamente, foram realizadas sedação, tricotomia e anti-sepsia da região, e anestesia local com lidocaína (Figuras 9 e 10).

O procedimento consistiu numa incisão de pele de aproximadamente $3 \mathrm{~cm}$, divulsão do tecido subcutâneo e retirada de um fragmento ósseo com um punch de $8 \mathrm{~mm}$ de diâmetro, acoplado em uma furadeira de baixa rotação. O fechamento da incisão foi realizado com sutura de pele padrão festonado com fio de nylon agulhado $\mathrm{n}^{\circ} 0$. 


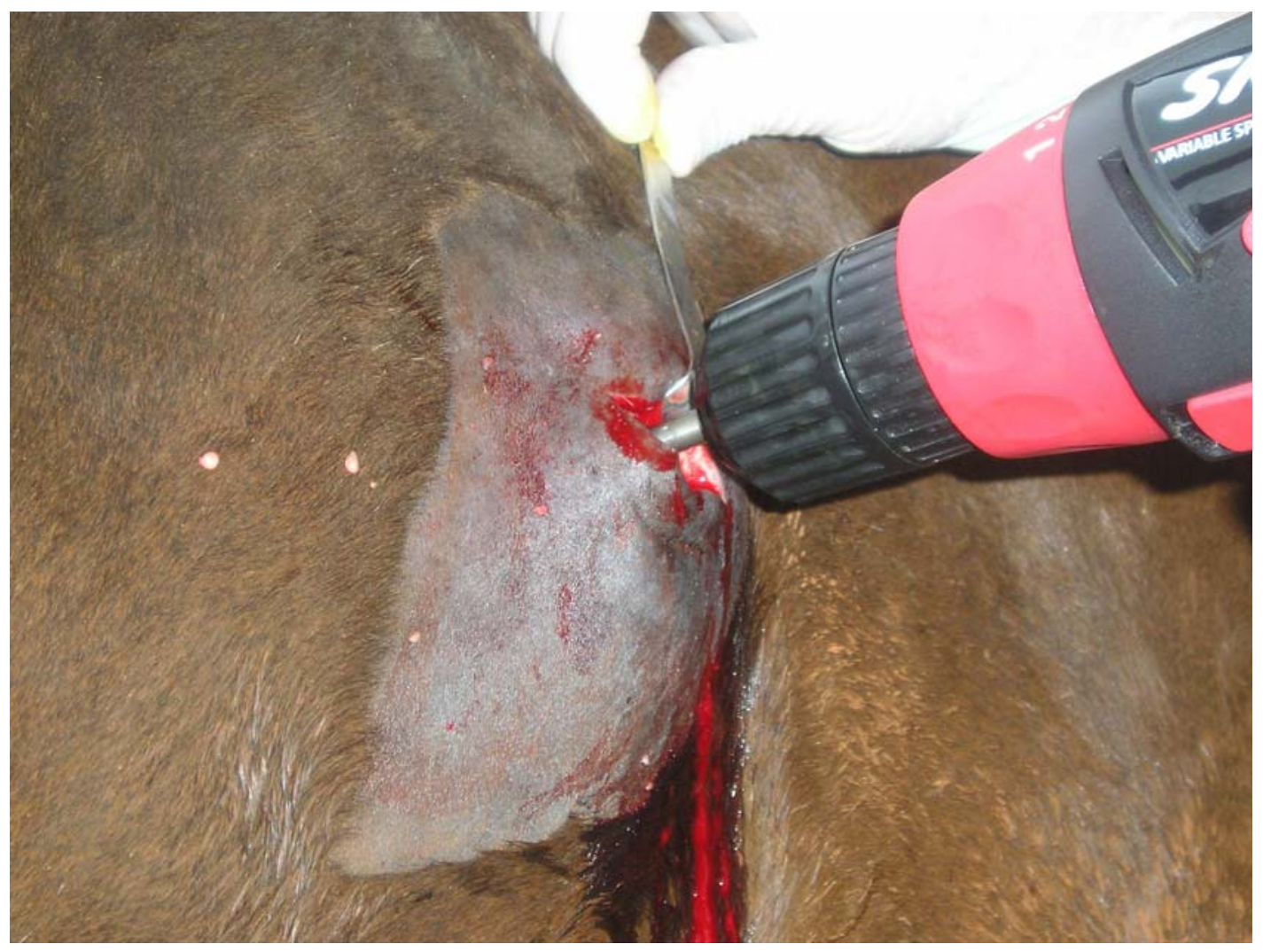

Figura 9 - Incisão da pele com divulsão do tecido subcutâneo por onde foi introduzida furadeira de baixa rotação para retirada do fragmento ósseo

O fragmento ósseo coletado foi acondicionado em álcool $70 \%$ para posterior análise de Cálcio e Fósforo (Figura 11), no laboratório de bioquímica do Departamento de Tecnologia da Universidade Estadual Paulista, Campus de Jaboticabal, São Paulo. 


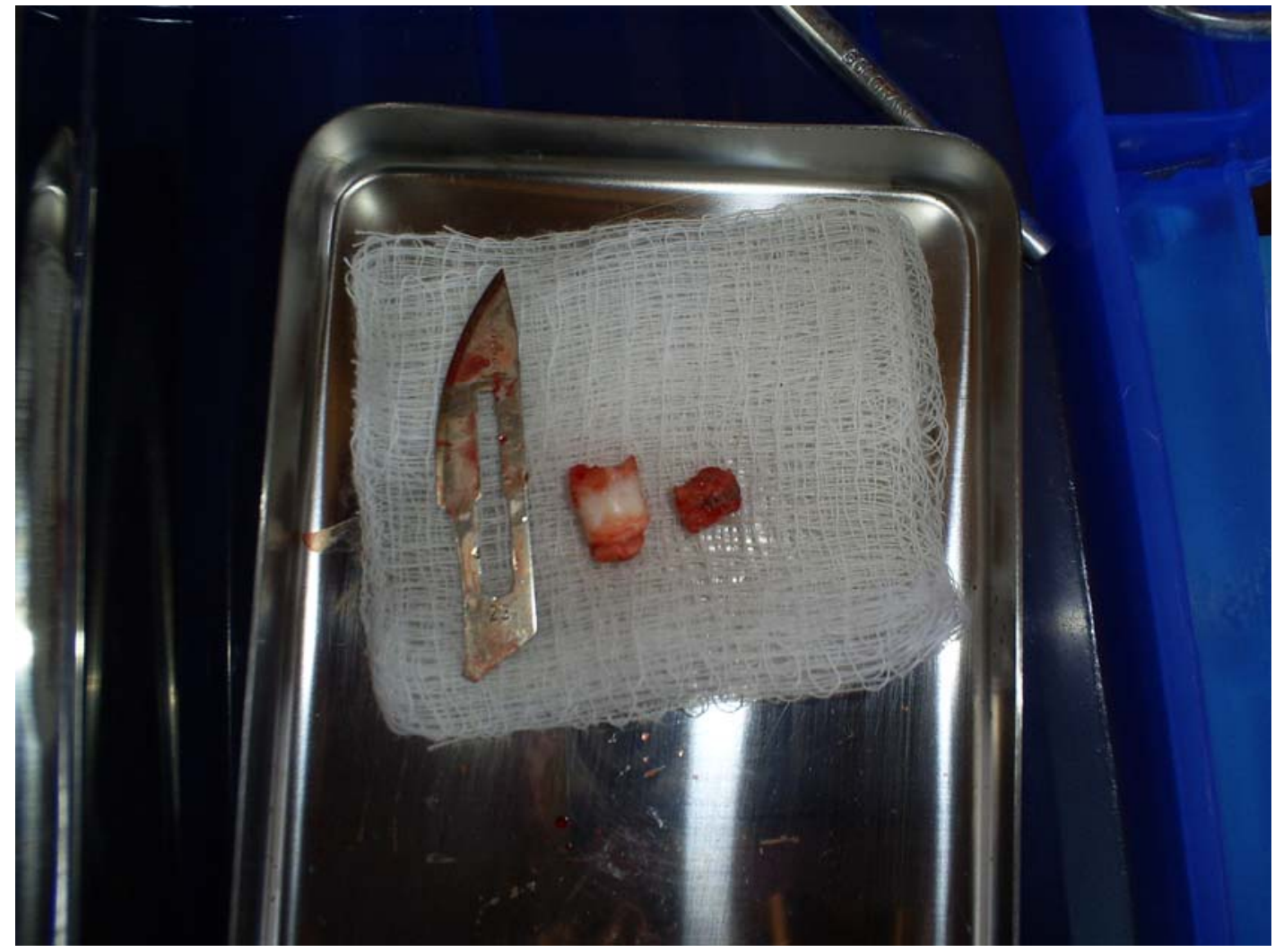

Figura 10 - Fragmento ósseo, comprando seu tamanho com a lâmina do bisturi

A metodologia para determinação da concentração de Cálcio e Fósforo nas cinzas ósseas foi seca e desengordurada, acondicionada em mufla na temperatura de $600^{\circ} \mathrm{C}$ por $6 \mathrm{~h}$. As cinzas foram solubilizadas a quente utilizando-se solução de ácido clorídrico 50\%. O Cálcio foi determinado por espectrofotometria de absorção atômica e o Fósforo determinado por espectrofotometria. 


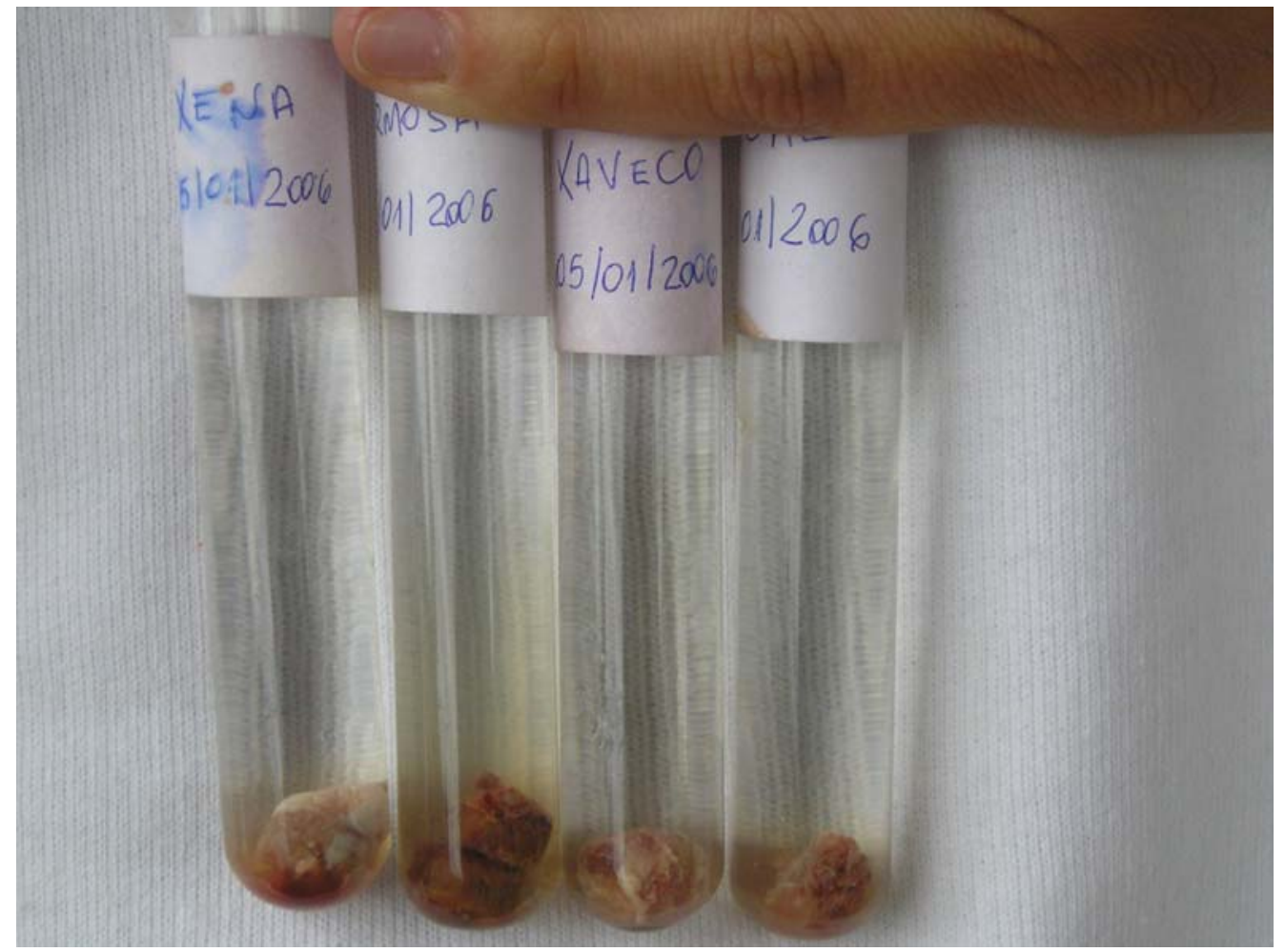

Figura 11 - Amostra de fragmentos ósseos acondicionados em álcool 70\% com a identificação de cada animal e data da coleta para posterior analise

\subsection{Densitometria óssea}

$\mathrm{Na}$ avaliação da DMO, utilizou-se a técnica de densitometria óptica em imagem radiográfica que baseia-se no estudo com escala de referência, sendo o alumínio utilizado como matéria-prima padrão para confecção da cunha e posterior obtenção de resultados em equivalentes em peso linear de alumínio por quilo em metros (peso linear kg/m), técnica similar a descrita por Plotnick et al. (1970) e citado por Vulcano et al. (2006).

A escala foi utilizada como referencia para calibragem do sistema de comparação entre as densidades evitando desta maneira as possíveis variáveis que este método poderia apresentar, minimizando, assim, as diferenças no padrão radiográfico entre os filmes analisados (VULCANO et al., 2006). Essa escala de 
alumínio apresentava $22 \mathrm{~cm}$ de altura, $1,85 \mathrm{~cm}$ de lado e a sua profundidade variando de $0,80 \mathrm{~cm}$ a $2,60 \mathrm{~cm}$.

Portanto, para a realização das radiografias, utilizou-se aparelho de raio-x portátil modelo FNX Jockey 90 , chassi Konex de tamanho $24 \times 30 \mathrm{~cm}$, contendo filme radiográfico de marca Kodak MXG 24×30cm. O Écran Kodak Lanex Regular era inserido em um chassi radiográfico, no qual se fixou uma escala de alumínio (penetrômetro).

Os fatores de exposição utilizados foram $46 \mathrm{kV}$ e $0,8 \mathrm{mAs}$, com distância focofilme de $60 \mathrm{~cm}$. A projeção radiográfica utilizada foi a latero-medial e dorso-palmar, que proporcionou imagem da articulação metacarpofalangeana, juntamente com a escala de alumínio, para avaliação da densidade mineral óssea. Os filmes radiográficos foram revelados em processadora automática. A escolha da articulação metacarpofalangeana para ser radiografado se deu pela presença do osso do terceiro metacarpo que é exclusivamente cortical, de fácil acesso, sem a presença de outros órgãos ou estruturas que possam atrapalhar a radiografia e a medição da cicatriz epifisária (MOURA, 2001).

A avaliação era realizada a cada 30 dias até completar os 90 dias do experimento (Figura 12).

A DMO foi determinada, utilizando-se scanner, para digitalizar as imagens radiográficas e em seguida, um programa computacional (ImageJ) foi utilizado para determinação e análise da densidade óptica das imagens digitalizadas e da cunha de alumínio, sendo analisado a quantidade de pixels da cunha de aluminio e da cicatriz epifisária no terceiro metacarpo (Figuras 13 e 14).

O programa ImageJ define a quantidade de pixels da área correspondente a cicatriz epifisária e da cunha de aluminio, desta forma foi possível mensurar a altura e a profundidade na cunha de aluminio e correlacionar com a densidade mineral óssea com a densidade do alumínio em peso linear em $\mathrm{kg} / \mathrm{m}$, os dados foram transformados posteriormente em porcentagem por não ser a medida em peso linear em $\mathrm{kg} / \mathrm{m}$ a mais usual para a densitometria óssea. 


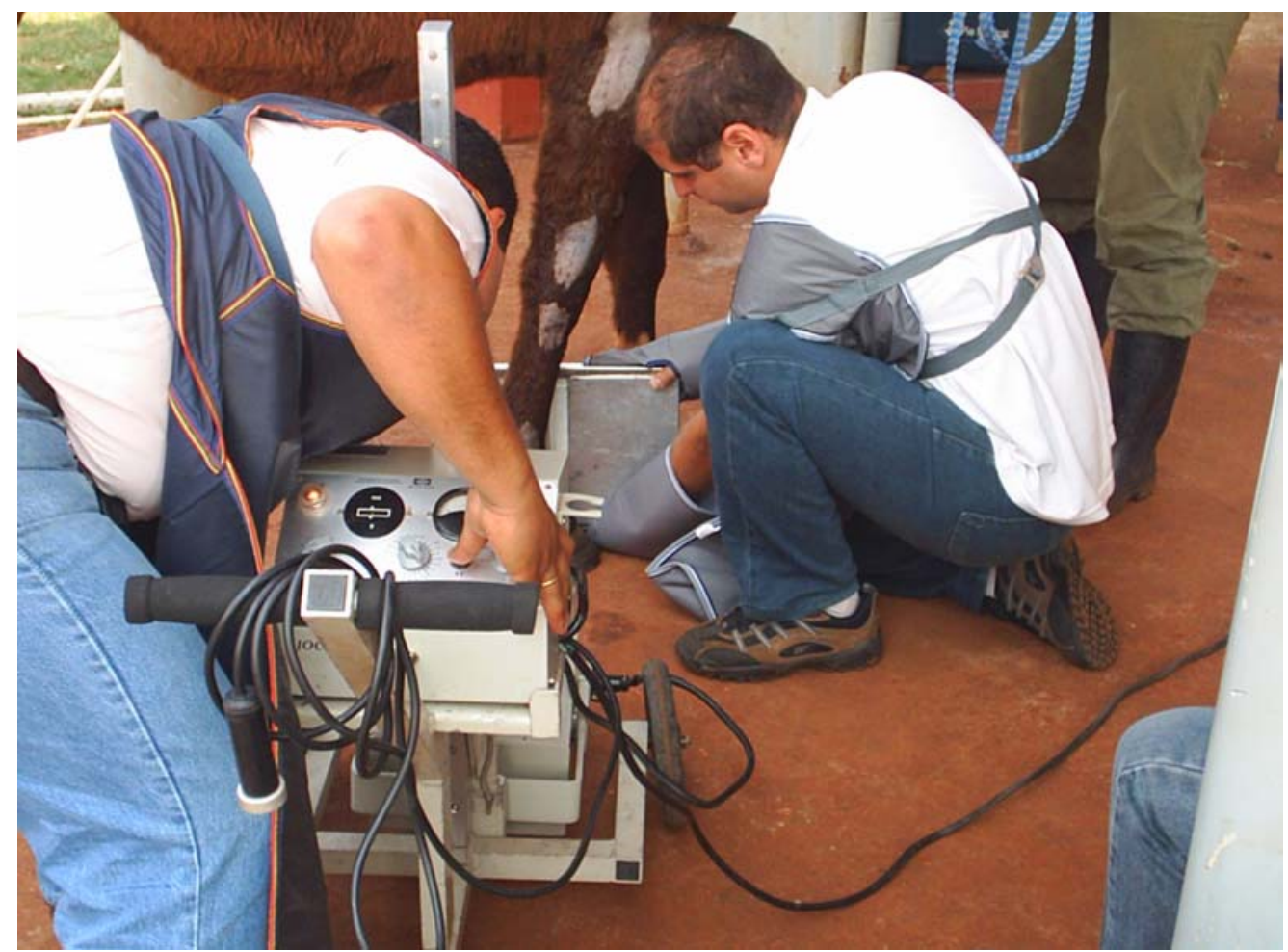

Figura 12 - Radiografia do membro anterior direito na posição latero-lateral e dorsopalmar, com aparelho portátil

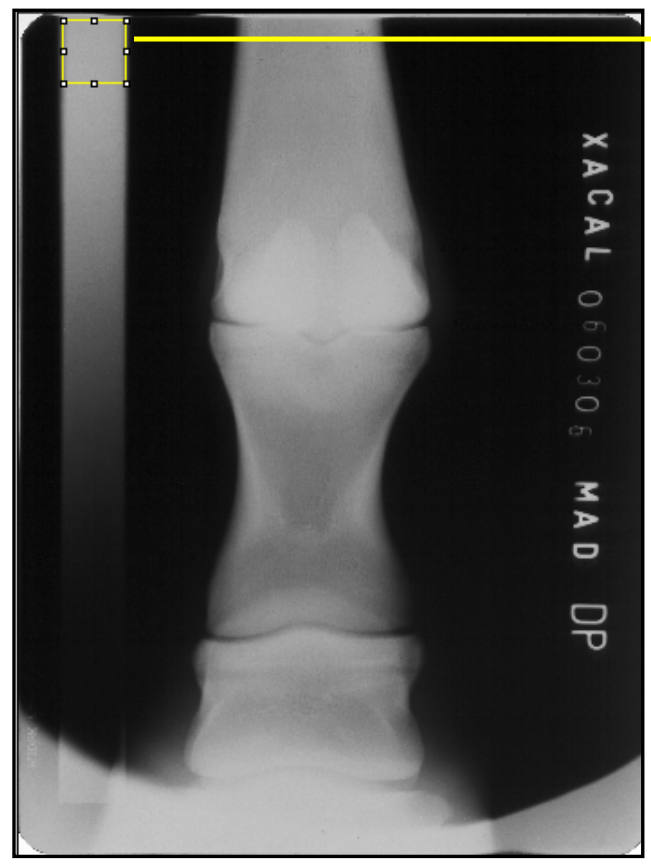

\subsection{3 pixels Seleção} (cunha)

Figura 13 - Seleção da área da cunha e determinação da quantidade de pixels 


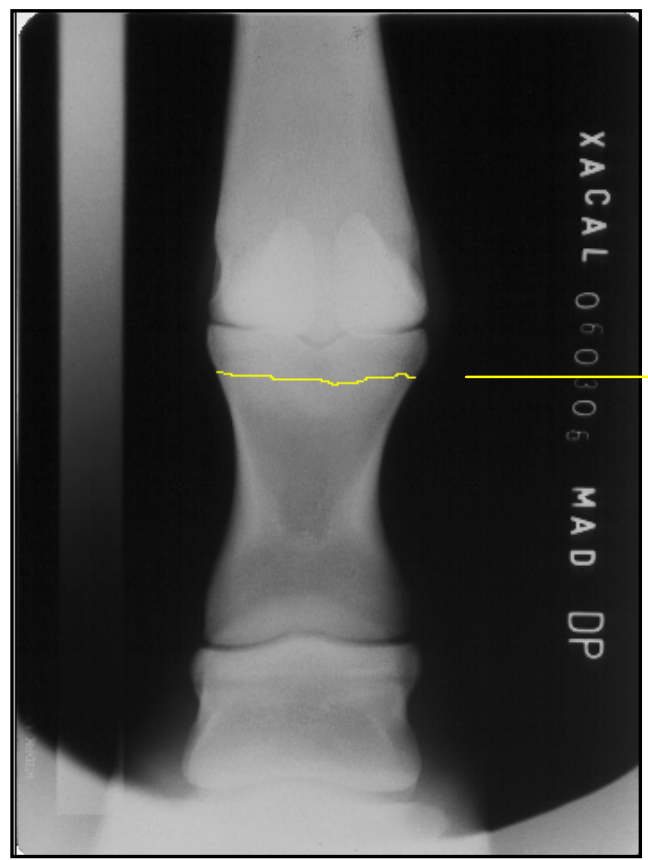

140.616 pixels

Cicatriz epifisária

Figura 14 - Seleção da área da cicatriz epifisária e determinação da quantidade de pixels

\subsection{Delineamento experimental}

O delineamento experimental aplicado foi inteiramente casualizado com dois tratamentos: T (tratamento) - mistura mineral orgânica; C (Controle) - mistura mineral inorgânica, com cinco repetições por tratamento e medidas repetidas no tempo.

\subsection{Análise estatística}

Os resultados obtidos foram analisados pelo programa computacional Statistical Analysis System (SAS Institute, 1998), sendo anteriormente verificada a normalidade dos resíduos pelo Teste de Shapiro-Wilk (PROC UNIVARIATE) e as variâncias comparadas pelo Teste de Hartley. Os dados originais foram submetidos à análise de variância, que separou como causas de variação o efeito da alimentação 
com minerais orgânicos e inorgânicos em potros. Variáveis: consumo de concentrado, feno, sal mineral, ganho de peso médio e diário, deposição de Cálcio, Fósforo, altura de cernelha, garupa, perímetro torácico, joelho e canela foram analisadas através do teste de analise de variância (ANOVA). Tal análise foi realizada utilizado-se o procedimento General Linear Model (PROC GLM do SAS).

Para a variável resposta densitometria óssea, a análise estatística foi realizado pelo Software Instat versão 3.01 e ANOVA pareada seguida do TukeyKramer de comparações múltiplas. 


\section{RESULTADOS E DISCUSSÃO}

Os dados coletados e analisados foram organizados e separados e estão apresentados a seguir.

\subsection{Dieta}

Como esperado e com base nas exigências nutricionais NRC (1989) não houve diferença para os parâmetros de consumo de concentrado, feno e sal mineral, conforme tabela 6.

Tabela 6 - Resultados obtidos para as médias de consumo de feno, concentrado e sal mineral orgânico e inorgânico $(\mathrm{kg})$ durante o período experimental, e os respectivos coeficientes de variação $(\mathrm{CV} \%)$ e probabilidade estatística $(\mathrm{P})$ para os modelos estudados Pirassununga - SP - 2006

\begin{tabular}{ccccc}
\hline & Inorgânico & Orgânico & P. & CV\% \\
\hline Feno & 1,96 & 2,07 & 0,3575 & 8,82 \\
Concentrado & 1,53 & 1,64 & 0,4518 & 14,99 \\
Sal mineral & 0,045 & 0,048 & 0,5475 & 18,92 \\
\hline
\end{tabular}

\subsection{Biopsia óssea}

Os resultados obtidos para a concentração mineral nos ossos e os valores médios para cada tempo entre o tratamento e o controle estão apresentados nas tabelas 7e 8. Os valores médios da deposição mineral óssea entre os tratamentos, Tmineral orgânico e C- mineral inorgânico, estão apresentados na tabela 9. 
Tabela 7 - Resultados referente à biopsia óssea para o tratamento e controle, bem como a deposição (Dep.) de cálcio e fósforo nos ossos - Pirassununga - SP - 2006

\begin{tabular}{|c|c|c|c|c|c|c|}
\hline Tratamento & Dupla (animal) & tempo & $\mathrm{Ca} \%$ & Dep. Ca, \% & $\mathrm{P} \%$ & Dep. P, \% \\
\hline \multirow{4}{*}{ orgânico } & \multirow{4}{*}{1} & 1 & 4,01 & 0,00 & 2,03 & 0,00 \\
\hline & & 2 & 11,68 & 7,67 & 5,78 & 3,75 \\
\hline & & 3 & 14,01 & 2,33 & 6,79 & 1,01 \\
\hline & & 4 & 14,30 & 0,29 & 7,08 & 0,29 \\
\hline \multirow{4}{*}{ inorgânico } & \multirow{4}{*}{1} & 1 & 5,93 & 0,00 & 2,94 & 0,00 \\
\hline & & 2 & 10,01 & 4,08 & 4,83 & 1,89 \\
\hline & & 3 & 12,41 & 2,40 & 5,97 & 1,14 \\
\hline & & 4 & 11,08 & $-1,33$ & 5,75 & $-0,22$ \\
\hline \multirow{4}{*}{ orgânico } & \multirow{4}{*}{2} & 1 & 5,57 & 0,00 & 2,65 & 0,00 \\
\hline & & 2 & 8,25 & 2,68 & 4,34 & 1,69 \\
\hline & & 3 & 10,92 & 2,67 & 6,05 & 1,71 \\
\hline & & 4 & 13,47 & 2,55 & 7,07 & 1,02 \\
\hline \multirow{4}{*}{ inorgânico } & \multirow{4}{*}{2} & 1 & 8,42 & 0,00 & 3,68 & 0,00 \\
\hline & & 2 & 9,60 & 1,18 & 3,16 & $-0,52$ \\
\hline & & 3 & 11,39 & 1,79 & 5,40 & 2,24 \\
\hline & & 4 & 13,16 & 1,77 & 6,52 & 1,12 \\
\hline \multirow{4}{*}{ orgânico } & \multirow{4}{*}{3} & 1 & 6,63 & 0,00 & 3,29 & 0,00 \\
\hline & & 2 & 7,08 & 0,45 & 3,54 & 0,25 \\
\hline & & 3 & 8,06 & 0,98 & 3,52 & $-0,02$ \\
\hline & & 4 & 9,02 & 0,96 & 4,24 & 0,72 \\
\hline \multirow{4}{*}{ inorgânico } & \multirow{4}{*}{3} & 1 & 6,29 & 0,00 & 3,07 & 0,00 \\
\hline & & 2 & 13,61 & 7,32 & 6,53 & 3,46 \\
\hline & & 3 & 14,30 & 0,69 & 6,55 & 0,02 \\
\hline & & 4 & 14,62 & 0,32 & 7,76 & 1,21 \\
\hline \multirow{4}{*}{ orgânico } & \multirow{4}{*}{4} & 1 & 7,44 & 0,00 & 3,38 & 0,00 \\
\hline & & 2 & 18,94 & 11,50 & 8,87 & 5,49 \\
\hline & & 3 & 19,19 & 0,25 & 9,07 & 0,20 \\
\hline & & 4 & 19,20 & 0,01 & 9,49 & 0,42 \\
\hline \multirow{4}{*}{ inorgânico } & \multirow{4}{*}{4} & 1 & 11,39 & 0,00 & 5,27 & 0,00 \\
\hline & & 2 & 12,20 & 0,81 & 5,98 & 0,71 \\
\hline & & 3 & 13,17 & 0,97 & 7,14 & 1,16 \\
\hline & & 4 & 17,67 & 4,50 & 8,43 & 1,29 \\
\hline \multirow{4}{*}{ orgânico } & \multirow{4}{*}{5} & 1 & 8,25 & 0,00 & 4,10 & 0,00 \\
\hline & & 2 & 17,20 & 8,95 & 8,31 & 4,21 \\
\hline & & 3 & 17,95 & 0,75 & 8,81 & 0,50 \\
\hline & & 4 & 17,66 & $-0,29$ & 7,32 & $-1,49$ \\
\hline \multirow{4}{*}{ inorgânico } & \multirow{4}{*}{5} & 1 & 6,62 & 0,00 & 3,17 & 0,00 \\
\hline & & 2 & 9,07 & 2,45 & 5,33 & 2,16 \\
\hline & & 3 & 11,82 & 2,75 & 6,36 & 1,03 \\
\hline & & 4 & 12,32 & 0,50 & 6,61 & 0,25 \\
\hline
\end{tabular}


Tabela 8 - Valores médios de Cálcio e Fósforo para cada tempo entre o tratamento e o controle - Pirassununga - SP - 2006

\begin{tabular}{lccc}
\hline Tratamento & Tempo & $\mathrm{Ca}$ & $\mathrm{P}$ \\
\hline Orgânico & 1 & 6,38 & 3,09 \\
Inorgânico & 1 & 7,73 & 3,63 \\
Orgânico & 2 & 12,63 & 6,17 \\
Inorgânico & 2 & 10,89 & 5,15 \\
Orgânico & 3 & 14,03 & 6,85 \\
Inorgânico & 3 & 12,62 & 6,29 \\
Orgânico & 4 & 14,73 & 7,04 \\
Inorgânico & 4 & 13,77 & 7,01 \\
\hline
\end{tabular}

Tabela 9 - Valores médios da deposição mineral óssea de cálcio e fósforo durante o período experimental, coeficiente de variação $(\mathrm{CV} \%)$ e probabilidade estatística $(\mathrm{P})$ para os tratamentos com mistura mineral orgânica e inorgânica - Pirassununga - SP - 2006

\begin{tabular}{lcccc}
\hline \multicolumn{5}{c}{ Tratamento } \\
\hline & Orgânico & Inorgânico & P. & CV\% \\
\hline Cálcio \% & 11,94 & 11,25 & 0,7111 & 35,60 \\
Fósforo \% & 5,91 & 5,52 & 0,7564 & 35,38 \\
\hline
\end{tabular}

Apesar de não ter sido observada diferença significativa, o resultado obtido com o uso da mistura mineral orgânico possibilitou numericamente uma maior retenção mineral óssea de Cálcio e Fósforo, sendo benéfico para animais em crescimento e inicio de atividade física, pois nesse momento o tecido ósseo é sensível a diversos fatores nutricionais, tais como deficiência de Cálcio. A maior deposição de íons inorgânicos, principalmente o Cálcio, é importante, pois faz com que ocorra a mineralização da matriz óssea. Acredita-se que esse resultado ocorreu pelo pequeno número de repetições, ou pelo curto período da fase de coleta de amostra. 
Os resultados diferem dos obtidos por Ott e Johnson (2001), que, obtiveram menor concentração óssea de minerais para o tratamento com minerais orgânicos, porém sem diferença estatística.

Quando comparado com o estudo realizado por Nielsen et al. (1998b) que estudaram o efeito da suplementação mineral em potros, utilizando diferentes concentrações de Cálcio e Fósforo na dieta, observou que os animais que receberam uma concentração maior de Cálcio tiveram maior retenção de Cálcio que os animais controle $(\mathrm{P}<0,05)$. E que o aumento do incremento de Cálcio poderá promover benefícios no processo de remodelação óssea e no crescimento ósseo. Entretanto, Leeson e Summers (1997) observaram que o aumento dos níveis de minerais inorgânicos não seria possível, pois segundo eles ocorre efeito negativo de um mineral em altas doses na absorção de outro mineral.

Com as divergências nos resultados dos estudos realizados com o aumento dos níveis de minerais, e levando em consideração que altos níveis de minerais inorgânicos podem ser prejudiciais devido às interações negativas, os resultados numéricos aqui encontrados podem indicar maior biodisponibilidade dos minerais orgânicos e melhor deposição mineral óssea.

Os resultados obtidos quando contrastados com os resultados de literatura mostram que as informações sobre os minerais orgânicos ainda são muito controversas quando se discute melhora na retenção de minerais nos ossos e em animais em crescimento. Esse fato pode ser explicado pela quantidade de várias moléculas quelatadas existentes e suas diferenças na biodisponibilidade e estabilidade, bem como no seu metabolismo.

\subsection{Avaliação de desenvolvimento}

Os resultados obtidos para as variáveis perímetros de canela, joelho e torácico bem como para altura de garupa, cernelha e ganho de peso estão apresentados na tabela 10. Não foi observada diferença significativa para essas 
variáveis, entretanto o ganho de peso médio e diário foi melhor $(P<0,05)$ para a mistura com mineral orgânico.

Tabela 10 - Resultados obtidos para os valores médios em centímetros das avaliações de desenvolvimento dos potros, sendo elas: perímetro de canela (PC), de joelho (PJ), torácico $(\mathrm{PT})$, altura de garupa $(\mathrm{AG})$, de cernelha $(\mathrm{AC})$, além dos resultados para ganho de peso médio (GPM/kg) e ganho de peso diário (GPD/kg), bem como os respectivos coeficientes de variação $(\mathrm{CV} \%)$ e probabilidade estatística (P.) Pirassununga - SP - 2006

\begin{tabular}{cccccc}
\hline & \multicolumn{2}{c}{ Tratamento } & & \\
\cline { 2 - 3 } & Orgânico & Inorgânico & & P. & CV\% \\
\hline PC $(\mathrm{cm})$ & 18,58 & 17,54 & & 0,1743 & 7,63 \\
PJ $(\mathrm{cm})$ & 30,53 & 29,11 & & 0,2056 & 5,64 \\
PT $(\mathrm{cm})$ & 152,34 & 148,13 & & 0,2094 & 5,05 \\
AG $(\mathrm{cm})$ & 142,34 & 137,77 & & 0,0867 & 3,84 \\
AC $(\mathrm{cm})$ & 139,03 & 135,14 & & 0,1339 & 3,53 \\
GPM $(\mathrm{kg})$ & $92,8^{\mathrm{a}}$ & $78^{\mathrm{b}}$ & & 0,0267 & 10,11 \\
GPD $(\mathrm{kg})$ & $1,007^{\mathrm{a}}$ & $0,845^{\mathrm{b}}$ & & 0,0288 & 10,38 \\
\hline
\end{tabular}

* letras diferentes na mesma linha diferem estatisticamente entre si pelo teste $F(P<0,05)$

Esses resultados para desenvolvimento animal corroboram com os obtidos por Ott et al. (2001), que avaliaram a suplementação de minerais proteinados em comparação a de minerais na forma inorgânica. Exceção para altura da garupa, que foi significativamente maior para nos animais que receberam os minerais proteinados, e para ganho de peso, cuja diferença em favor dos minerais orgânicos foi apenas numérica. 


\subsection{Densitometria óssea}

O resultado para a variável resposta, densitometria óssea, está apresentado no gráfico 1. Foi observado um incremento significativo na deposição óssea dos animais tratados com minerais orgânicos $(P=0,011)$. Aos 90 dias do período de coleta das amostras, esses animais apresentaram maior densidade óssea quando comparado aos animais do tratamento controle. Apesar de ter havido diferença numérica ele não foi significativo.

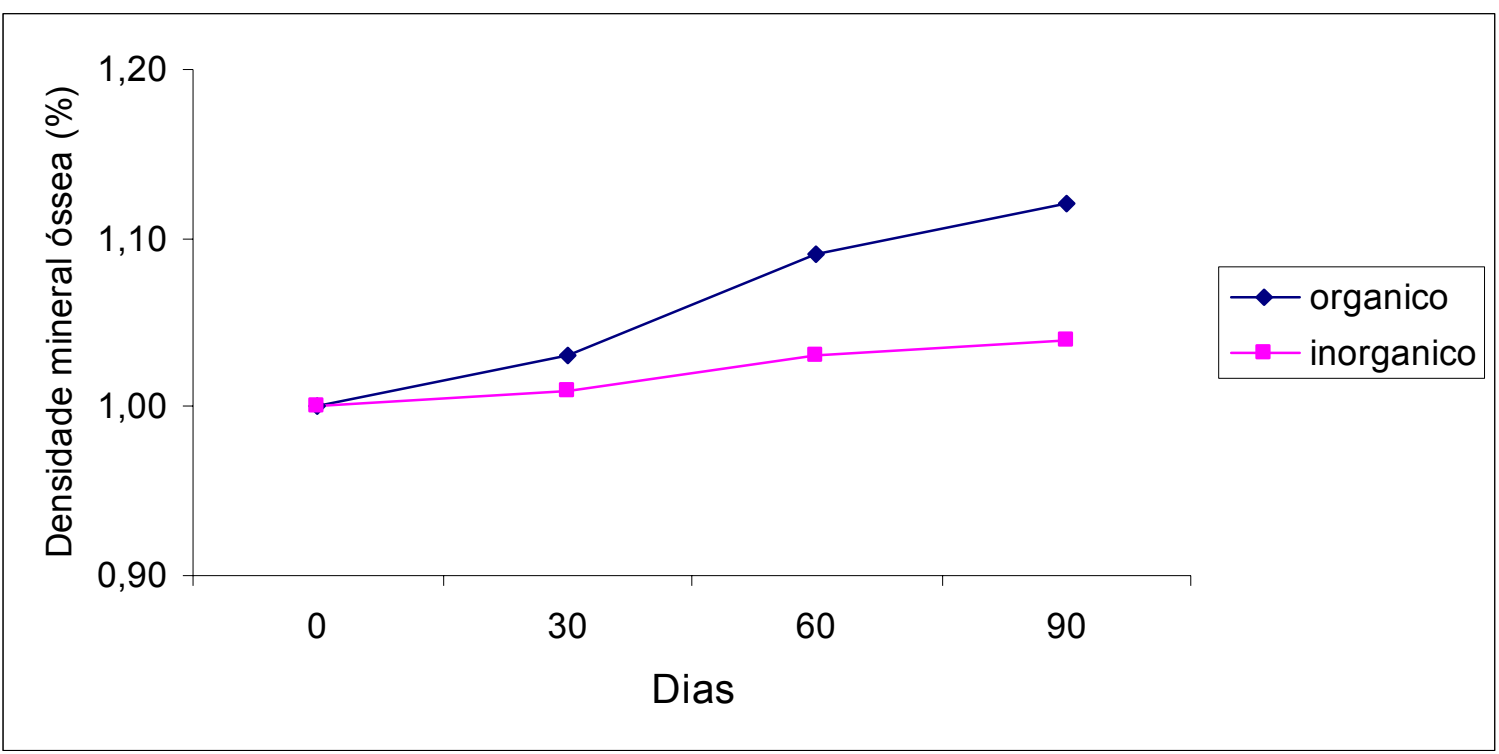

Gráfico 1 - Resultados obtidos para os valores da densitometria óssea nos animais tratados com minerais orgânicos e inorgânicos, correspondentes aos dias 0, 30, 60 e 90, levando em consideração que todos os animais apresentavam valores iguais ao inicio do experimento - Pirassununga - SP - 2006

De acordo com Lawrence et al. (1994), a densidade óssea influencia a resistência óssea a injurias. Segundo os mesmo autores a técnica de aferição biomecânica dos ossos é um bom meio para medir a biodisponibilidade dos minerais nos ossos.

McCarthy e Jeffcott (1992) observaram incremento na densidade óssea em potros em atividade física comparado com aqueles em inatividade. Já Porr et al. (1998) verificaram diminuição da densidade mineral dos ossos da diáfise medial, 
metáfise medial e metáfise lateral de animais que permaneceram por 12 semanas em descondicionamento físico, independente do nível de Cálcio na dieta ou do aumento da concentração sérica de Cálcio.

O presente experimento teve o mesmo tempo de duração do trabalho de Porr et al. (1998) e os animais também ficaram mantidos em cocheiras, sem atividade física, entretanto, o fornecimento de Cálcio na forma orgânica proporcionou maior deposição óssea do que o mesmo nível de Cálcio suplementado na forma inorgânica.

Este aumento na retenção de minerais nos ossos promove benefícios no processo de remodelação óssea em todo do sistema esquelético (Nielsen et al., 1998a) entretanto, quando os autores suplementaram com maior quantidade de $\mathrm{Ca}$ (34,9g/dia) e P (26,4g/dia) comparado com o grupo controle Ca $(28,3 \mathrm{~g} / \mathrm{dia})$ e $P$ $(21,9 \mathrm{~g} / \mathrm{dia})$ em animais em treinamento, eles não obtiveram diferença na deposição óssea entre os tratamentos, porém houve uma tendência de melhor deposição no grupo que foi suplementado em maiores quantidades de minerais.

No estudo realizado por Buchholz-bryant (2001), com diferentes quantidades de Cálcio e Fósforo na dieta de eqüinos, foi observado melhor resultado na retenção de Ca de P quando acima das recomendações do NRC (1989) em 275\% comparado com o controle $100 \%$ da recomendação do NRC (1989).

Neste experimento foi observado que a suplementação com minerais orgânicos na mesma quantidade que os inorgânicos pode produzir melhor resposta na retenção de minerais nos ossos, sem a necessidade de aumentar a quantidade do nível de suplementação mineral como foi realizado nos experimentos de Nielsen et al. (1998a); Porr et al. (1998) e Buchholz-bryant (2001).

No que se refere à técnica de mensuração óssea para deposição de mineral nos ossos, foi observado diferenças no resultado entre a técnica de biópsia óssea para deposição de minerais quando comparado com a técnica de densitometria óssea. De acordo com o estudo realizado por McCarthy e Jeffcott (1992) nenhuma diferença significativa que comprometa a mensuração invasiva e não invasiva foi observada para deposição óssea. 
Já para Karen et al. (2000), com avanço da tecnologia e muitas ferramentas e métodos de avaliação para a deposição óssea, a técnica de densitometria seria um método não invasivo muito eficaz de avaliar a densidade óssea, técnica que seria mais aplicável e permitiria realizar muitas pesquisas em eqüinos. 


\section{CONCLUSÃO}

O uso de minerais orgânicos quando comparado com inorgânicos na alimentação de potros proporcionou maior ganho de peso, sem influenciar os parâmetros de crescimento e a deposição de Cálcio e Fósforo nos ossos. Foi observado aumento na densidade óssea, o que pode ser promissor para promover benefícios na remodelação e crescimento ósseo.

Novos estudos com o uso de minerais orgânicos precisam ser realizados para obtenção de mais informações.

Com relação às técnicas realizadas para as mensurações de deposição de minerais nos ossos, a técnica da densitometria óssea deve ser melhor avaliada, ou seja, mais trabalhos devem ser realizados para sua comprovação, já que os resultados obtidos com ela e com a biópsia foram divergentes. 


\section{REFERÊNCIAS}

AOAC. ASSOCIATION OF OFFICIAL ANALYTICAL CHEMISTS. Official methods of analysis. 16th ed. Arlington: AOAC International, 1995. 2 v. p.1025

ASSOCIATION OF AMERICAN FEED CONTROL OFFICIAL (AAFCO). Official Publication. Atlanta, 1997.

BELL, R. A.; NIELSEN, B. D.; WAITE, K.; ROSENSTEIN, D.; ORTH, M. Daily access to pasture turnout prevents loss of mineral in the third metacarpus of Arabian Weanlings. Journal of Animal Science, v. 79, p. 1142-1150, 2001.

BONDI, A. A. Nutrición del caballo y para la producción de trabajo. Zarogoza, Espanha: Nutrición Animal. 1988. p. 481.

BUCHHOLZ-BRYANT, M. A.; BAKER, L. A.; PIPKIN, J. L.; MANSELL, B. J; HALIBURTON, J. C.; BACKMAN, R. C. The effect of calcium and phosphorus supplementation, inactivity, and subsequent aerobic training and mineral balance in young, mature, and age horses. Journal of Equine Veterinary Science, v. 21, n. 2, p. 71-77, 2001.

CABRAL, G. C.; ALMEIDA, F. Q.; QUIRINO, C. R.; AZEVEDO, P. C. N.; PINTO, L. F. B.; SANTOS, E. M. Avaliação morfológica de eqüinos da raça Mangalarga: Índices de conformação e proporções corporais. Rio de Janeiro. Revista Brasileira de Zootecnia, v. 33, n. 6, p. 1798-1805, 2004.

CADORE, E. L.; BRENTANO, M. A.; KRUEL, L. F. M. Efeitos da atividade física na densidade mineral óssea e na remodelação do tecido ósseo. Revista Brasileira de medicina do Esporte, v. 11, n. 6, p. 373-379, 2005.

CAZES, R. L.; SOARES, A. Minerais orgânicos na nutrição de eqüinos. In: SIMPÓSIO SOBRE NUTRIÇÃO DE EQÜINOS, 1., 2004, Campinas. Anais... Campinas: Colégio Brasileiro de Nutrição Animal - CBNA, 2004. p. 61-75.

CHITOLINA, J. C.; GLORIA, N. A. Complexos e quelatos - equilibrios de um processo de complexação. titulações complexometricas e quelatometricas. Piracicaba. Escola Superior de Agronomia Luiz de Queiroz - ESALQ, 1991, p. 3- 7. 
CLYDESDALE, F. M. Mineral interactions in foods. In: BODWELL; C. E.; ERDMAN, JR., J. W. Nutrient interactions. New York: Marcel Dekker, 1998. p. 257-268.

GETTY, R. Anatomia dos animais domésticos. 5. ed. Rio de Janeiro: Guanabara Koogan, 1986. V. 1, p. 19-31

HINEY, K. M.; NIELSEN, B. D.; ROSENSTEIN, D. Short-durantion exercise and confinement alters bone mineral content and shape in weanling horses. Journal of Animal Science, v. 82, p. 2313-2320, 2004.

HOEKSTRA, K. E.; NIELSEN, B. D.; ORTH, M. W.; ROSENSTEIN, D. S.; SCHOTT, H. C.; SHELLE, J. E. Stalling young horses alters normal bone growth. Kentucky Equine Research. In: Reprint courtesy of Kentucky Equine Research. p. 165-166. 2007. Disponível em: <http:// www.ker.com>. Acesso em: 20 jan 2007.

HOFFMAN, R. M.; LAWRENCE, L. A.; KRONFELD, D. S.; COOPER, W. L.; SKLAN, D. L.; DASCANIOS, J. J.; HARRIS, P. A. Dietary carbohydrates and fat influence radiographic bone mineral content of growing foals. Journal of Animal Science, v. 77, p. 3330-3338, 1999.

IMAGEJ. Image Processing and Analysis in Java: Versão 1.39f.13 out, 2006.

Disponível em: <http://www.rsb.info.nih.gov>. Acesso em: 01 de novembro de 2006.

JACKSON, S. G.; PAGAN, J. D. Development orthopedic desease. Multiple causes No sure cures., Journal of Equine Veterinary Science, v. 13, n. 1, p. 9, 1993.

JUNQUEIRA, L. C.; CARNEIRO, J. Tecido ósseo. In: ed. Rio de Janeiro; Guanabara Koogan, 1995, p. 108-123. Histologia básica. 8.

KAREN, L.; WAITE, M. S.; BRIAN, D.; NIELSEN, B. D.; DIANA, S. R. Computed tomography as a method of estimating bone mineral content in horse. Journal of Equine Veterinary Science, v. 20, n. 1, p. 49-52, 2000.

LAWRENCE, L. A.; OTT, E. A.; MILLER, G. J.; POULOS, P. W.; PIOTROWSKI G; ASQUITH, R. L. The mechanical properties of equine metacarpals as affected by age. Journal of Animal Science, v. 72, p. 2671-2623, 1994. 
LEESON, S.; SUMMERS, J. D. Commercial poultry nutrition. 2. ed. Guelph, Ontario: University Books, 1997. P. 57-58.

LEY, W. B.; THATCHER, C. D.; SWECHER, W. S.; LESSARD, P. N. Chelated Mineral supplementation in the barren mare: a preliminary trial. Equine Veterinary Science, v. 10, n. 3, p. 176, 1990.

LEWIS, D. L. Nutrição para os eqüinos: Alimentação e cuidados. São Paulo: Roca, 2000. p. 18-24.

LIMA, R. A. S.; SHIROTA, R.; BARROS, G. S. C. Estudo do complexo do agronegócio cavalos. Piracicaba: Escola Superior de Agronomia Luiz de Queiroz ESALQ, 2006, p. 5-9.

MABE, I. Efeitos da suplementação dietética com quelatos de zinco e de manganês na produção de ovos e morfologia intestinal de galinhas poedeiras. 001. 94 f. Tese (Doutorado) - Faculdade de Ciências Farmacêuticas, Universidade de São Paulo, 2001.

MALLETO, S. Allá riscoperta dei mineralli. Informatone Zootécnico, v. 44, p. 51-84, 1997.

MCCARTHY, R. N.; JEFFCOT, L. B. Effects of treadmill exercise on cortical bone in the third metacarpus of young horse. Research in Veterinary Science, v. 52, p. 2837, 1992.

MCLLWRAITH, C. W. The equine skeleton: how does bone grow and how do abnormalities in developmental process affect soundness? Colorado: Colorado State University, 1996.

MOURE, A. Construção de um protótipo de densitômetro ósseo para uso em clínica de grandes animais. 2001. 52 f. Dissertação (mestrado em ciências) Centro Federal de Educação Tecnológica do Paraná, Engenharia Elétrica e Informática Industrial, Curitiba/PR, 2001. 
NRC. NATIONAL RESEARCH CONCIL OF THE NATIONAL ACADEMIES. Nutrient requirements of horses. 5. ed. Washington, NRC, 1989.p. 1089.

NRC. NATIONAL RESEARCH CONCIL OF THE NATIONAL ACADEMIES. Nutrient requirements of horses. 6. ed. Washington: NRC, 2007. P. 70-78.

NIELSEN, B. D.; POTTER, G. D.; GREENE, I. W.; MORRI, F. I.; MURRAY-GERZIK, M.; SMITH, W. B.; MARTIN, N. P. Characterization of changes related to mineral balance and bone metabolism in the young racing quarter horse. Journal of Equine Veterinary Science, v. 18, n. 3, p. 190-200, 1998a.

NIELSEN, B. D.; POTTER, G. D.; GREENE, I. W.; MORRI, F. I.; MURRAY-GERZIK, M.; SMITH, W. B.; MARTIN, N. P. Response of young horses in training to varying concentration of dietary calcium and phosphorus. Journal of Equine Veterinary Science, v. 18 , n. 6 , p. 397-404, 1998b.

OOM, M. M.; FERREIRA, J. C. Estudo biométrico do cavalo alter. Revista

Portuguesa de Ciências Veterinárias, v. 83, n. 482, p. 101-148, 1987.

ORTOLANI, E. L. Macro e microelementos. In: SPINOSA, H. S.; GÓRNIAK, S. L.; BERNARDI, M. M. Farmacologia aplicada à medicina veterinária. 1. ed. Rio de Janeiro: Guanabara Koogan, 1996. 545 p.

OTT, E. A.; ASQUITH, R. L. The influence of mineral supplementation on growth and skeletal development of yearling horses. Journal of Animal Science, v. 67, p. 28312840, 1989.

OTT, E. A.; ASQUITH,R. L. Trace mineral supplementation of broodmares. Journal of Equine Veterinary Science, v. 14, n. 2, p. 93, 1994.

OTT. E. A.; JOHNSON, E. L. Effect of trace mineral on growth and skeletal and hoof development in yearling horses. Journal of Equine Veterinary Science, v. 21, n. 6, p. 287-292, 2001. 
PAGAN, J. P. Developmental orthopedic disease: a new perspective. Kentucky Equine Research. In: R Equine Research. p. 475 - 479. 2000. Disponível em: http://www.ker.com. Acesso em: 20 janeiro de 2007.

PETER, R.; MOURE, A.; REMIGIO, H. G. Bone mineral content of the third metacarpal bone in quarter horse foals from birth to one year of age. Journal of Equine Veterinary Science, v. 24, n. 9, p. 391-396, 2004.

PRADA FILHO, J. R. C.; STERMAN, F. A. Avaliação da densidade mineral óssea em potros da raça Puro Sangue Inglês em ínicio de treinamento. São Paulo. Brazilian Journal of Veterinary Research and Animal Science, v. 41, n. 6, p. 384-388, 2004.

PORR,C. A.; KRONFELD, D. S.; LAWRENCE, L. A.; PLEASANT, R. S.; HARRIS, P. A. Deconditioning reduces mineral content of the third metacarpal bone in horses. Journal of Animal Science, v. 76, p. 1875-1879, 1998.

SAS. STATISTICAL ANALISYS SYSTEM. SAS user's guide: statistics. Versão 6. Cary-NC: SAS Institute, 1998. 578 p.

SARAIVA, G. L.; CASTRO, L. M. Marcadores bioquímicos da remodelação óssea na prática clínica. São Paulo. Arquivo Brasileiro de Endocrinol Metabolismo, v. 16, n. 1, p. $72-78,2002$.

SECHINATO, A. S. Efeito da suplementação dietética com micro minerais orgânicos na produção e qualidade de ovos de galinhas poedeiras. 2003. $68 \mathrm{f}$. Dissertação (Mestrado em Nutrição Animal) - Faculdade de Medicina Veterinária e Zootecnia, Universidade de São Paulo, Pirassununga, 2003.

SOUZA, A. A.; BOIN, C. Minerais quelatados. Radares técnicos-nutrição, 2002. Disponível em: <http:// www.beefpoint.com.br>. Acesso em: 16 ago 2006. 
SPEARS, J. W. Optimizing mineral levels and sources for farm animal. In: KORNEGAY, E. T. Nutrient management of food animals to enhance and protect the environment. New York: CRC Press, 1996. p. 259-275.

STASHAK, T. S. Claudicação em eqüinos Segundo Adams. 4. ed. São Paulo: Roca, 1994. p. 503-513.

SWENSON, M. J.; REECE, W. O. Ossos. Articulações e líquido sinovial. In: WASSERMAN, R. H.; KALLFELZ, F. A.; GEORGE, L. Dukes fisiologia dos animais doméstico. 11. ed. Rio de Janeiro: Guanabara Koogan, 1996. p. 488-508.

VANDERGRIFT, B. The role of mineral proteinates in immunity and reproduction what do we really know about them. In: PROCEEDINGS OF ALLTECH'S ANNUAL SYMPOSIUM: BIOTECHNOLOGY IN THE FEED INDUSTRY, 9., 1993. 27 p.

VILELA, M. L. A. Tecidos que formam o esqueleto ósseo. Disponível em:<http://www.afh.bio.br>. Acessado em: 22 jun 2007.

VULCANO, L. C.; MENDES, R. G.; GODOY, C. L. B.; MACHADO, V. M. V.; BICUDO, A. L. C. Padronização da densidade mineral óssea (DMO) do acessório do carpo em eqüinos atletas da raça Quarto de Milha. Santa Maria. Ciência Rural, v. 36, n. 2, p. 520-424, 2006.

WOLTER, R. Dietética do cavalo atleta. In: SIMPÓSIO INTERNACIONAL DE NÃO RUMINANTES, 1992, Lavras. Anais... Lavras, MG: Simpósio Brasileiro de Zootecnia, 1992. p. 273-312. 